\title{
DIE KOMODIEN DER MRS. CENTLIVRE. \\ II.
}

\section{Dritter teil.}

Kritik der komödien unter zugrundelegung der quellen.

Die hier behandelten vierzehn stücke sind sämtlich als comedies bezeichnet, obwohl eines, St. H., eher ins gebiet der tragikomödie gehört. Die meisten stehen auf der grenze zwischen lustspiel und posse.

Sie bestehen sämtlich aus je fünf akten und sind vielfach aus mehreren handlungen zusammengesetzt, die oft nicht das mindeste mit einander $\mathrm{zu}$ tun haben. Die verbindung ist dann dadurch hergestellt, dals eine oder mehrere personen der einen handlung als verwandte von personen der andern handlung bezeichnet werden. Am schroffsten tritt dieser mangel an einheit in St. H. hervor. - Es gibt andrerseits stücke, die melırere handlungen aufweisen, aber doch einheitlich verlaufen, endlich eins, B. Str., das in jeder hinsicht einheitlich ist. Dazwischen sind alle möglichen spielarten vorhanden, insbesondere, wenn man noch das verhältnis der episoden zu den eigentlichen handlungen in betracht zieht. ') Mafsgebend für das zusammenfügen mehrerer nicht zusammengehöriger handlungen war wohl neben der tradition sowohl der wunsch, das stück trotz enger anlehnung an andere als selbständig erscheinen zu lassen, als auch die notwendigkeit, fünf akte zu füllen.

Die stücke sind alle mit einem prolog und einem epilog versehen; das publikum war daran gewöhnt und verlangte

1) S. die auf diesen beziehungen beruhende analyse der stücke in der oben (Anglia. N. F. XX s. 436) genannten dissertation. 
sie; sie haben meist mehr oder weniger enge beziehung zum inhalt; sie empfehlen die komödie der gunst der zuschauer und sind nicht immer von der verfasserin selbst gedichtet. Im folgenden werden sie nur erwähnt, wenn sie besondere beziehungen enthalten.

Die stücke haben durchweg eine schnelle und gute exposition. Meist führt schon der erste akt alle einigermalsen wichtigen personen vor. Selten tritt eine person, die in die handlung eingreift, erst in einem späteren akt auf, wie etwa colonel Merryman in P. L. im dritten akt.

Soweit die stücke den oben erwähnten mangel an einheit aufweisen, wechseln szenen der einen und solche der anderen handlung mechanisch mit einander ab. Immerhin ist mit sichtlicher sorgfalt darauf geachtet, dafs in dem fernhalten der personen von der bühne eine gewisse gleichmäIsigkeit herrscht. Das auf- und abtreten der personen geschieht oft recht willkürlich und unmotiviert.

Der szenenwechsel ist häufig, z. b. auch in P. L., so schnell, daIs eine drehbühne am platze wäre.

Der knoten der verwicklung ist meist gut geschürzt; um so mehr fällt es auf, dafs der dichterin der sinn für die dramatische lösung mehrfach abgeht. Es wird sich bei der betrachtung der einzelnen stücke zeigen, dafs am schlufs zuweilen ein deus ex machina eingeführt wird, der im grunde genommen den ganzen apparat der fünf akte überflüssig macht. Doch sind das ausnahmen.

Am schlufs werden stets alle personen auf der bühne vereinigt, auch meist diejenigen, die nach der entwicklung des stückes nichts mehr dort zu suchen haben, wie der entlarvte Tally in A. - Die bösen holen sich dabei den letzten fufstritt, die guten werden in der freude des letzten lachens gezeigt. Bisweilen herrscht natürlich, um diese vereinigung herbeizuführen, der grölste zwang, der oft ohne ein wort der motivierung angewendet wird. - Eine andere damit zusammenhängende eigentümlichkeit ist die, dafs das stück immer über den schlufs der handlung hinausführt; manchmal wird den hineingefallenen noch die list erklärt, deren opfer sie sind (L.C.); manchmal werden auch noch die dienstbaren geister unter allerhand scherzen durch die ehe vereint (L.V.), u. a. mehr. Den 
abschlufs bildet dann, wie ja auch jetzt noch auf bühnen, die der volkstümlichen poesie dienen, musik, gesang und tanz, bisweilen ein zum inhalt des stückes in beziehung stehendes couplet.

Die sprache der Mrs. Centlivre ist vielfach getadelt worden, und mit recht; trotzdem sie die fähigkeit zu edlem ausdruck besitzt, ist die sprechweise vieler personen niedriger als ihr gesellschaftlicher rang. - Vielfach liebt sie es, die ausdrucksweise der personen ihrer stellung und herkunft anzupassen, und mit erfolg. Vom dialekt macht sie reichlichen gebrauch. - Der ausdruck ist im allgemeinen kräftig. Die dialogführung ist stets munter, oft witzig und bisweilen geistreich. Die antithesé, ausrufe der gemütsbewegungen - des lachens, der freude, der überraschung, des unwillens - der doppelsinn, das wortspiel, die ironie, der zank, die logische widerlegung mit eignen worten, nachsprechen, alles wird herangezogen, um den dialog frisch zu erhalten. Reichlichen gebrauch macht sie von seitenbemerkungen, ebenso von zwischenbemerkungen dritter personen. - Gemütsbewegungen, zorn, traurigkeit, erstaunen, inneren widerstand, begeisterung weils sie vorzüglich zu malen. - Besonders im ersten akt zeigt sie eine hohe fähigkeit, uns mit den personen durch ihre unterhaltung überraschend schnell vertraut zu machen, so dals wir sie vor uns zu sehen glauben; in dem ersten oder den beiden ersten akten ist denn auch die charakteristik am besten. In den späteren wächst der dichterin - sie arbeitete offenbar häufig viel zu schnell - der stoff über den kopf, so dals die charakteristik nicht klar genug durchgeführt wird.

Noch von einer andern seite her erleidet diese durchführung einbufse: dadurch, dafs die dichterin der traditionellen possenmotive nicht entraten kann. Wenn wir von einer charakteristik sprechen, so ist dabei durchaus hervorzuheben, dafs sie durch die verwendung der personen zu possenmotiven oft gänzlich durchbrochen wird. So steht in B. D. das erscheinen der mädchen beim duell der gecken in gar keinem verhältnis zu ihrem charakter. Dieses beispiel könnte beliebig vervielfacht werden. Erst wenn man die allzu gewaltsam, unorganisch hineingezwungenen possenscherze abzieht, erscheint der charakter, wie er aus worten und handlungen hervorgeht, und wie wir ihn in der dissertation für jede person 
festgestellt haben, um die charakterisierungsgabe der dichterin - und darauf kommt es uns an - zu erkennen.

Modifiziert wird das urteil über diese und andere fähigkeiten der Mrs. Centlivre ebenfalls durch die heranziehung der quellen. Es sind noch nicht alle quellen bekannt; die bereits gefundenen werden im folgenden in betracht gezogen. Es wird, um zu einem urteil über die dichterin zu gelangen, nötig sein festzustellen, ob sie sich sklavisch an die vorlage bindet oder selbständig denkt. Ergibt sich, dafs sie das letztere tut, so werden ihre charaktere und ihre ansichten als ihr geistiges eigentum auch unter der voraussetzung gelten können, dafs die an- und entlehnungen in wahrheit umfangreicher sind als man bis jetzt weils oder je feststellen wird. Ist doch bei so ausgedehnter tätigkeit eine gänzliche selbständigkeit der dichterin überhaupt unmöglich. Das material wird eklektisch zusammengetragen, und damit wird der neue bau errichtet. Dann liegt auch in der übernahme der idee die billigung, und die tatsache der billigung kann dann die möglichkeit bieten, uns die schaffende persönlichkeit menschlich näher zu bringen.

Nunmehr gehen wir zur besprechung der einzelnen stücke über.

Mrs. Centlivre begann ihre literarische und dramatische tätigkeit mit einer tragödie: 'The Perjured Husband, die 1700 veröffentlicht wurde. Dieses stück verrät in den tragischen teilen kein talent. Es hat aber auch eine lustige nebenhandlung, die von manchen (Genest) geschätzt, von anderen (Ward) verworfen wird. Wer auch recht habe, die komischen teile zeigen mehr begabung als die ernsten, und man kann wohl annehmen, dafs Mrs. Centlivre, die ihr geschmack zur tragödie zog, erst durch diese wirkung auf das gebiet der komödie gelenkt wurde, das mehr erfolg versprach. In der Biogr. dram. ist als zweites werk L.C. angegeben; dem folgen alle älteren aufzählungen. Erst in neueren findet man umstellungen, die sich den aufführungsdaten fügen. Danach wäre die reihenfolge: B. D., St. H., L. C.; die drucke beweisen nichts wesentliches, da St.H. ohne datum gedruckt ist. Nun ist L.C. ein schon in dem engen anschlufs an Molière sehr unreifes werk. B. D. ist ihm bedeutend überlegen. Eine zwischenstufe zwischen dem erstlingswerk und B. D. ist sehr wahrscheinlich. Vielleicht ist daher die aufzählung in den älteren biographischen werken 
der niederschlag der tatsache, dafs L.C. so früh gedichtet, aber erst später auf die bühne gebracht ist. - Wie dem auch sei, es soll hier mit der besprechung dieses werkes begonnen werden.

L. C. 1) hat ein vorwort, in dem auseinandergesetzt wird, daIs zwischen den berufsmä Isigen kritikern und dem publikum ein unterschied nach der seite hin bestehe, dafs jene das nach antikem muster aufgebaute drama verlangen, dieses durch scherzhafte und witzige vorführungen unterhalten sein will. Der dichter müsse sich schliefslich dem verlangen des publikums fügen. Das habe sie mit dem vorliegenden werk getan, das teilweise Molière entlehnt sei. Nur habe sie bisweilen etwas stärker auftragen müssen, denn der Engländer sei beim scherz schwerfälliger als der Franzose. - Sie rühmt ferner die wohlanständigkeit des stückes. Über den erfolg sei sie erstaunt gewesen; doch verdanke sie ihn zum grofsen teil den vorzüglichen leistungen der schauspieler.

Das stück ist mit grofser lebendigkeit geschrieben. Es enthält eine reihe von szenen, die sehr komisch wirken, z. b. die zwischen Octavio und Sir Toby (I), ferner die szenen, in denen Martin auftritt, und die unterhaltungen Doubtfuls mit den vermeintlichen gelehrten (V).

Moralisch steht es verhältnismäIsig tief. Dafür sei folgende stelle angeführt $(I, 1)$ :

Lucinda: ... In short, Sir, if you won't consider my Body, have some Pity for my Soul, for I am certain I shall -

Selfwill: Cuckold him, ha - let him look to that. ... Daughter of mine, this is no Excuse.

Man bedenke, dafs hier ein vater mit seiner tochter spricht!

Ferner: als Beliza in sachen ihrer kusine zu Bellmie eilt, trifft sie nicht ihn, sondern seinen freund Octavio, der ihr wie ein roher mann einer feilen dirne entgegen tritt. Aber das hindert nicht, dafs sich in das herz des mädchens der keim der liebe senkt!

Der sinn der handlung soll wohl der sein, dals durch allerhand intriguen einem bejahrten bewerber die lust zum heiraten verdorben wird. Dieser gedanke ist auch durchge-

1) Über die abkürzungen s. Anglia N.F. XX s. 434.

Anglia. N. F. XXI. 
führt, aber nicht allein. Es ist damit der zweite gedanke verknüpft, dals unter der vom vater her drohenden gefahr die liebenden immer erneute anstrengungen machen, einander zu gewinnen. Diese würden ins gebiet der episoden gehören, wenn nicht durch sie eine an sich unwesentliche beschleunigung des väterlichen planes herbeigeführt würde. - Ferner könnte man erwarten, dals durch das zurücktreten des bejahrten bewerbers das glück der liebenden begründet wird. Aber auch das ist nicht der fall. Die lösung, dafs sich die liebenden hinter dem rücken des vaters trauen lassen, um ihn mit der vollendeten tatsache zu überraschen, und seinen zorn und seine rache heraufbeschwören, wäre am anfang des stückes ebenso möglich gewesen wie am ende. Eine ironie des zufalls wäre allerdings verloren gegangen: nämlich, dafs eben der pfarrer, den der vater für seinen heiratskandidaten bestellt hat, die liebenden verbindet.

Die quellen sind mehrfach behandelt worden. Hohrmann (S. Centlivre's Verhältnis zu Molière und Regnard, Ztschrft. für vergleichende Literaturgeschichte. N. F., bd. 14) kommt über die abhängigkeit zu folgenden ergebnissen. DaIs Sir Toby aus seinem hause kommt, seinen dienern weisungen gibt, Octavio trifft und ihn um rat bittet, stammt aus Le Mariage forcé. Die entlehnungen sind an manchen stellen wörtlich. Oft ist S. C. derber, sie fügt zynische bemerkungen hinzu. Der streit zwischen Martin und seiner frau ist, vom schluls abgesehen, eine sinn- und teilweise auch wortgetreue wiedergabe aus Le Médecin malgré lui. Auch hier macht die dichterin vulgäre zusätze. Die nachahmung bleibt hinter dem original zurück. - Die list der tochter, sich plötzlich stumm zu stellen, stammt aus Le Médecin malgré lui; ebenso der gedanke, Martin als arzt auszugeben. - Die unterhaltung, die Lucinda und Doubtful über die ehe führen, stammt fast wörtlich aus Le Mariage forcé; ebenso der rat Octavios, die gelehrten zu befragen, und die unterredungen mit den gelehrten. - Die einleitung des englischen dramas wurde vielleicht durch den eingang von Sganarello ou le Cocu imaginaire veranlafst. Dorther stammt vielleicht auch die szene, in der das junge mädchen die treue des geliebten gegen die zweifel ihrer freundin verteidigt. - In dramatisch-technischer beziehung zeige sie zwar selbständigkeit, aber sie erniedrige die "sozial- 
satirische posse zum intriguenstück". So kommt Hohrmann zu dem urteil: "Es ist Sus. Centlivre nicht gelungen, aus den verschiedenen stoffen ein bedeutendes ganzes zu schaffen. Die behandlung des entlehnten ist recht äufserlich, und wir können ihrer kompilation keinen erheblichen literarischen wert beimessen." Aber Wülleweber (S. C.'s Love's Contrivance und seine Quellen. Diss. Halle 1900) und Ohnsorg (J. Lacy's Dumb Lady, Mrs. S. Centlivre's Love's Contrivance, Henry Fielding's Mock Doctor. Rostocker diss. Hamburg 1900) kommen zu ergebnissen, die für die dichterin höchst schmeichelhaft sind. Dieser scheinbare widerspruch erklärt sich daraus, dafs die beiden letzteren die persönlichen fähigkeiten der Mrs. Centlivre ins auge fassen, Hohrmann aber den literarhistorischen wert des werkes. Des letzteren tadel schliefst der anderen lob nicht aus. Das stück enthält aufser den zahlreichen entlehnungen auch wesentliche selbständige teile. Das ergebnis der kompilierung ist etwas neues. Aber es ist kein meisterwerk, sondern eine anfängerarbeit.

Höher steht ohne zweifel das nun folgende stück, B. D., das ein bestimmtes thema behandelt, nämlich das lächerliche des geckentums. Die quellen sind noch nicht bearbeitet. Bekannt ist bisher nur, dals Mrs. Plotwell's heirat und was damit zusammenhängt, aus Mayne's City Match stammt. Dieses stück erschien im jahre 1639. Der inhalt ist kurz folgender: Ein onkel Warehouse und ein vater Seathrift wollen sich überzeugen, ob ihre erben, der neffe Plotwell, bezw. der sohn Timothy, ihrem lüderlichen lebenswandel, wie sie versprochen haben, auch wirklich zu entsagen gewillt sind. Deshalb geben jene vor, geschäftlich eine seereise unternehmen zu müssen, und beauftragen einen alten diener, nach einiger zeit die nachricht zu verbreiten, sie seien ertrunken. Kaum sind die alten fort, da beginnen die jungen leute einen wüsten lebenswandel. Von einem streich ganz besondrer art - Timothy, sinnlos betrunken gemacht, wird, entsprechend ausgeputzt, als seltener fisch gegen eintrittsgeld gezeigt - sind die beiden alten in verkleidung zeugen; desgleichen, als die nachricht von ihrem tode bei den jungen männern die allergrö[ste freude hervorruft. - Nun geben jene sich zu erkennen und beschliefsen in ihrem zorn, die jünglinge durch enterbung zu strafen. Der onkel will zu diesem zweck sofort heiraten; wen, ist ihm ganz 
gleichgültig. So führt ihm ein heiratsvermittler (es ist übrigens der einst verarmte und als verschollen geltende vater Plotwells) ein mädchen Dorcas zu, die keine andere als die verkleidete tochter des alten Seathrift ist. Diese stellt sich vor der heirat fromm und züchtig, nachher frech und gemein. Der alte ist ganz verzweifelt. Da kommt der neffe, stellt ihm in aussicht, ihn von der frau zu befreien, macht ihn durch eine lüge - zwei wertvolle schiffe seien untergegangen - noch gefügiger, erwirbt sich seinen dank und seine verzeihung, die der onkel auch nicht zurücknimmt, als der wahre sachverhalt, dafs seine trauung so wie so ungültig ist, an den tag kommt. - Plotwell hat auch eine schwester, Penelope, die er, sie als schwester verleugnend, in der lebewelt die grofse dame spielen läIst, nachdem sie vorher nähmädchen gewesen war. Er stellt sie seinem freunde Timothy, der übrigens die rolle eines lächerlichen gecken spielt, als glänzende partie vor. Dieser fällt auf die list hinein, läfst sich mit Penelope trauen, und am schlufs nimmt sein vater die drohung mit der enterbung stillschweigend zurück.

Sus. Centlivre hat folgendes aus diesem stücke übernommen:

1. Eine bemerkung über Dorcas (II, 2), die hier mit dem heiratsplan in keiner verbindung steht:

"Yesterday I went To see a lady that has a parrot; my woman, while I was in discourse, converted the fowl;" usw. S. C. nimmt diese bemerkung in die unterhaltung, in der Toper dem alten Careful seine angebliche nichte empfiehlt (B.D. 105);

2. Einige züge, die Timothy insbesondere $\amalg, 6$ und IV, 3 als eingebildeten gecken zeichnen, für die gecken in B. D.;

3. Die tatsache, dafs der alte sich entschliefst, noch einmal zu heiraten;

4. Einige züge, mit denen der heiratsvermittler seine kandidatin in IV, 4 empiehlt (B. D. III, 103, 104);

5. Die wesentlichen einzelheiten der szenen, in denen die nunmehrige vermeintliche ehefrau dem alten als gemeine heuchlerin entgegentritt oder so von anderen geschildert wird (Mayne, $\mathrm{V}, 2-5$; wörtliche entlehnungen sind zahlreich; - Bellmeins rolle wird bei Mayne von dem wirt Roseclap gespielt);

6. Das hereintragen eines verhüllten bildes, das angeblich das schlafzimmer der jungen frau schmücken soll (V, 7; s. B.D. 
$\mathrm{V}, 124,125)$; diesem bilde entsteigen bei Mayne zwei männer, bei S.C. einer, nämlich Toper;

7. Die geheuchelte empörung der frau über des alten dreistigkeit, das bild zu enthüllen;

8. Die umkehr des alten, der seinerseits verzeihung verspricht, wenn er von dem weibe befreit werde.

Zunächst besteht die ähnlichkeit beider stücke darin, dafs der entschlufs des alten und seine übertölpelung nur den zweiten teil der handlung ausmachen, deren erster die grundlage für den zorn enthält. Die ersten partien sind ganz verschieden. Und die gänzlich andre motivierung gereicht dem späteren stück zum vorteil, denn die übertölpelung des alten sieht man wohl lieber, wenn sie dazu dient, einem braven liebespaar zum glück $7 u$ verhelfen, als einem jungen mann, dessen roheit bei dem vermeintlichen tode des onkels seinesgleichen sucht (Mayne, III, 3). Auch sind die jungen mädchen bei dieser übertölpelung in B.D. ferne zuschauer; die heuchlerin, die als vermeintliche ehefrau eine so gemeine rolle $\mathbf{z u}$ spielen weifs, ist in B.D. eine frau, die ihre "vergangenheit" hat, die nur, wie sie ausdrücklich entschuldigend hervorhebt, ihre reiche erfahrung in den dienst braver leute stellt. Dafs bei Mayne diese rolle, die so viel wissen schlimmster art voraussetzt, einem jungen mädchen zugedacht ist, erscheint nicht nur geschmacklos, sondern als ein zeichen ganz besonders roher lebensauffassung. Es sei ferner bemerkt, dals auch sonst die stellen gröbster sinnlichkeit selbst bei im übrigen wörtlicher übertragung fortgelassen sind. - Dals der heiratsplan bei Carefull länger vorbereitet ist als bei Warehouse, hebt die verständlichkeit seiner handlungsweise. - Im allgemeinen macht die ganze darstellung der übernommenen teile bei Mrs. Centlivre mehr den eindruck des mittels zum zweck. Alle veränderungen zeugen von besserem geschmack und feinerer gesinnung. Auch der zartere zug, dafs Carefull bedauert, eine tochter wegen eines bösen weibes verloren zu haben, soll der Centlivre nicht vergessen sein. - An eine mechanische übernahme der charakteristik ist nicht zu denken; bei Mayne sind die gestalten roh, die nüancen fehlen.

Der prolog des Centlivre'schen stückes klagt zunächst über die schwierigkeit, ein erfolgreiches stück zu schreiben, da einer in nachahmung der alten verfalsten tragödie zu 
leicht der vorwurf zu grofsen schwulstes, einer komödie der vorwurf des farcenhaften gemacht werde. Trotzdem habe die dichterin gewagt, ein stück darzubieten, das gleichsam dem tapferen krieger eine belohnung seiner mühsale sei. - Diese bedeutung hat das stück in der tat: der stutzer, der in putz und eitelkeit den zweck des lebens sieht, wird in mehreren exemplaren vorgeführt und in allen möglichen lagen zugunsten des soldaten lächerlich gemacht, sei es, dafs er bei der toilette seine läppischen gedanken äufsert, sei es, dafs er in all seiner erbärmlichen feigheit - lälst er sich doch sogar von verkleideten mädchen mit schlägen traktieren - gezeigt wird, sei es, daIs die verächtliche schwäche seines willens, selbst bei besserungsversuchen, ans licht kommt. Bei dem schönen geschlecht hat er so wenig erfolg, dafs er nicht einmal für die eifersüchtigen als nebenbuhler in betracht gezogen wird. - Dieses thema ist einer fabel eingepalst, die sich von den handlungen der andern stücke wesentlich unterscheidet. Es ist nämlich nicht die vereinigung des liebespaares das endziel, sondern die umstimmung des vaters der geliebten. Dieser, nicht ein solcher ausbund von gefühllosigkeit wie Selfwill (L.C.), hat gleichwohl die absicht, seiner tochter für ihren ungehorsam die erbschaft $\mathrm{zu}$ entziehen. Von diesem vorsatz wird er abgebracht, indem Mrs. Plotwell ihm klar macht, welchen gefahren er sich als bejahrter mann in einer ehe ohne jugendliche liebe aussetzt. - Das problem ist nicht musterhaft durchgeführt, aber man erkennt, wie Mrs. Centlivre von der reinen nachahmung abkommt und einem weniger äufserlichen stoff, dem gebiete der sitten und charaktere, ihr interesse zuwendet. Wir werden sehen, wie sie später auf diesem wege fortschreitet.

Der gröIste fehler in B. D. ist wohl seine zusammensetzung aus drei aufeinander folgenden handlungen. Es beginnt mit einer keineswegs unmöglichen verwechslung, deren opfer sowohl beide männer, Constant und Belmein, als auch beide mädchen, Clarinda und Emilia, sind. Sie mufs zu einer handlung führen, die in ihrem verfolg die verhängnisvollen wirkungen der verwechslung aufhebt. Selten hat die dichterin dieses motiv so glücklich verwendet wie hier. Leider nicht allein. Es folgt nun die überlistung des vaters und seines heiratskandidaten, und als dritter teil die bekehrung des vaters. 
- Der schlufs segelt, nicht allzu glücklich, unter der flagge der tugend: "Virtue, thou shining Iewel of my Sex - Thou precious Thing, that none knows how to value as they ought, while they enjoy it, but like spendthrift Heirs, when they have wasted all their Store, wou'd give the World they con'd retrieve their lost Estate: Therefore beware, you happy Maids, how you listen to the deluding Tongues of Men, 'tis only they have Power to betray you." Diese tirade klingt in dem munde einer Mrs. Plotwell nicht sehr geschmackvoll. Der nachdruck, der auf dieser und mancher ähnlichen äufserung der figur liegt, könnte fast (in erinnerung an ihr gleichwohl nicht verbürgtes jugendabenteuer) die vermutung aufkommen lassen, daIs die dichterin die genugtuung mitzufühlen ursache hatte, die Mrs. Plotwell in dem lob der leute äufsert, "who are better bred than to examine into past Conduct".

Im wesentlichen darf B. D. als versuch nach der seite des sittenstückes gelten, mit besonderer beziehung auf das geckentum, das sich im damaligen London, besonders auch im theater, breit genug machte. Doch ist auch der beobachtung der charaktere und ihrer schilderung schon ein wesentlicher raum zugeeignet. Wie indessen der erwähnte prolog zu B. D. zeigt, kommt der verfasserin der gedanke an die ernste dichtung nicht aus dem sinn. Und so erscheint denn als abstecher ins gebiet des tragischen St. H., denn wenn es auch "a comedy" genannt wird, so ist die eine hälfte dieses stückes ebenso gut eine tragödie wie The Cruel Gift, ${ }^{1}$ ) das, von einer auf der bühne gar nicht erscheinenden person abgesehen, auch unblutig endet. Die komische beigabe aber findet sich auch in dem als tragödie bezeichneten Perjur'd Husband. - Die richtigste bezeichnung für St. H. wäre tragikomödie. - Die quelle ist May's Heir; sie ist von Strube behandelt (S. Centlivre's The Stolen Heiress und sein Verhältnis zu The Heir von Thomas May. Diss. Halle 1900), dem wir im wesentlichen folgen. Die tragische handlung ist "von einigen nicht ins gewicht fallenden einzelheiten abgesehen" dieselbe wie in der quelle. - Im Heir lernen sich die liebenden erst im stück persönlich kennen; in St. H. ist die liebe zwischen Lucasia und Palante

1) Gedruckt 1717 . 
als schon bestehend angenommen, so dafs dadurch "die liebe und aufopferungsfähigkeit, die das paar später betätigt, verständlich, ja selbstverständlich wird". - Im Heir werden die liebenden festgenommen, ehe es zur trauung kommt. In St. H. findet die trauung vor der ergreifung statt, vielleicht wegen der szenen, die in Gravellos haus zur entdeckung der flucht führen, vielleicht auch, um die umkehr unmöglich zu machen; ein glücklicher griff ist diese änderung schon deshalb, weil "durch die trauung erst das eigentliche faktum der entführung geschaffen ist". - In der quelle hat sich die zofe durch geld bestechen lassen, das geheimnis zu verraten, in St. H. erliegt sie der augenblicklichen angst bei der bedrohung ihres lebens. Die änderung ist glücklich. - Im $\mathrm{H}$. ist der widerwille des vaters gegen den geliebten der tochter auf einen hals gegen des letzteren vater gegründet; von einem solchen hafs ist in St. H. nicht die rede; - gegen Strube läfst sich hier geltend machen, dafs dieser hals wohl den widerwillen Gravellos gegen Palante, nicht aber seinen lebhaften wunsch, Pirro als schwiegersohn heranzuziehen, erklären würde. Die durchführung in St. H. erscheint in dieser beziehung straffer. In St. H. eilt nach dem verrat der flucht Gravello der tochter nach, Pirro aber (abweichend von der quelle) zum statthalter. Auch hier scheint uns (gegen Strube) der vorzug Mrs. Centlivre zu gehören. Denn die ergreifung der fliehenden tochter ist sache des vaters; Pirros interesse aber ist es, sich den sieg auf dem rechtsweg zu sichern; auch scheint die ergreifung kaum zweifelhaft. - Nach der quelle konnte Eugenio erstaunt sein, von Pirro zum morde angestachelt zu werden; in St. H. bereitet der verkleidete einem solchen ansinnen die wege, indem er hals gegen Eugenio heuchelt. Die änderung war unnötig und erzwungen. Warum Clerimont, abweichend von der vorlage, den tod ebenfalls erleiden soll, ist unerfindlich. Die szene, in der die liebende dem machthaber gegenübertritt, ist gewaltig geändert. Im Heir macht jener dem mädchen den vorschlag, ihr zu verzeihen, wenn sie sich von ihm entehren lasse; in St. H. stellt er blofs die bedingung, den ihr vom vater aufgedrängten bräutigam zu heiraten. Mrs. Centlivre ändert also nach der moralischen seite hin; sie setzt sich allerdings dem, wenn auch nicht streng beweisbaren vorwurf aus, dals sie die vollziehung der trauung vergessen hat. - 
Eine verschlechterung ist in dem späten eingreifen Eugenios zu sehen; die erklärung "To let my Father see the Frailty - I will not call it by a harder Name - of Count Pirro" kann nicht genügen. Warum läfst er nicht wenigstens die verurteilten, mit denen er mehrere szenen hindurch allein ist, das geheimnis wissen, damit sie nicht den ganzen jammer der todesgewifsheit auskosten müssen? Darauf weist Strube sehr mit recht hin. - Andrerseits ist es wieder eine verbesserung, dals in St. H. Pirro verbannt wird; im Heir geht er straflos aus. - Zum schlufs fügt Mrs. Centlivre noch die bei ihr stets abschliefsende szene hinzu, in der alle personen versammelt werden.

Der charakter Roscos ist schärfer herausgearbeitet als der entsprechende der quelle. - Der vater (Gravello) ist roher als in der vorlage; insbesondere ist sein verhältnis zu seiner tochter unerfreulicher. - Pirros abscheulichkeit, auch in körperlicher beziehung, ist noch mehr hervorgehoben, um der abneigung Lucasias eine noch deutlichere grundlage zu geben.

Die zweite, die komische handlung, ist "total umgeformt, obwohl einzelne züge trotzdem die abhängigkeit vom Heir verraten". Sie betreffen zunächst den grundgedanken, dals "der vater seine tochter mit einem reichen, aber ungeliebten mann vermählen will". - In der szene, in der Lavinia sich als schwanger hinstellt, nähert sich die handlung wieder der des Heir; der vergleich schlägt zum vorteil der Mrs. Centlivre aus; das anstöfsige ist gemildert. Das entsprechende mädchen im Heir ist schwanger, Lavinia bezichtigt sich dessen nur, "jedoch unschuldig und nur unter dem einflufs der grölsten not".

Die art der verarbeitung der vorlage zeigt also auch bei diesem stück eine kritische selbständigkeit, wenn auch grolse bequemlichkeit. Das gesamturteil kann nicht sehr günstig ausfallen. Kaum ein zweites stück ist so sinnlos wie dieses aus zwei handlungen zusammengeschweifst, die nichts mit einander zu tun haben. Der bei weitem schwächere teil ist der tragische. In der list Gravellos feiert die gefühlsroheit einen triumph. Dals er selbst auseinandersetzt, der schmerz, den er heuchele, sei der grölste, den es gebe (I, 1), ist obendrein eine geschmacklosigkeit. Man wird bei dem tragischen teil vergeblich eine szene suchen, die sympathisch berührt. 
Die pathetischen tiraden der liebenden, die meist in blankversen gehalten sind, versteigen sich fortwährend zu geschmacklosen übertreibungen. - Erträglicher wäre die nebenhandlung, wenn sie nicht in solcher umgebung stände. Das stück hat eine berührung mit B.D., indem die gecken der lächerlichkeit ausgesetzt werden. Es wäre nicht unmöglich, herauszukonstruieren, dals St. H. früher liegt. Für den ruf der dichterin wäre es erfreulich, wenn dieses unter ihre ersten versuche gerechnet werden könnte. Sie hätte dann, durch den erfolg von L. C. und B. D. angeregt, mut gehabt, mit dieser früheren arbeit hervorzutreten. Dals sie selbst nicht übermälsiges vertranen dazu gehabt hat, beweist der umstand, dafs sie, wie der prolog zeigt, ihre urheberschaft verleugnete.

Jene änderung der chronologie gewinnt eine wahrscheinlichkeit mehr durch den umstand, dafs das folgende stück nicht nur als eine fortentwicklung von B. D. erscheint, sondern überhaupt eins der besten werke der dichterin ist. Sie leiht in G. auf einer ausgedehnten grundlage dem interesse ausdruck, das sie, wie die darstellung der gesinnungswandlung Carefulls in B.D. beweist, der beobachtung und schilderung von charakteren entgegenbrachte. - Die schablone wird beiseite gelegt; das abgeklapperte motiv von der unglücklichen tochter, die einen andern liebt als den ihr der vater bestimmt, tritt einmal zurück. Dabei steht eine einzige person im mittelpunkt, eben der spieler, der junge Valere. Inn liebt Angelica, der auch sein herz gehört; ihn umwirbt auch deren schwester, Lady Wealthy; um ihn sorgt sich sein vater und bemüht sich sein diener. Der bejahrte verehrer Angelicas, Dorante, bietet einen scharfen gegensatz $\mathrm{zu}$ ihm; Lovewell steht auch nicht ganz fern, hilft ihm doch Valere zum siege! So hat das stück eine glückliche, innere einheitlichkeit. Der schwerpunkt des stückes liegt aber nicht in intriguen, sondern in Valere selbst. In seinem innern führen die liebe zum spiel und die zu Angelica einen streit. Trotz dieser schwäche macht ihn uns seine frische, seine ehrenhaftigkeit sympathisch. Seine jugend und sein siegesbewuIstsein dem zorn der geliebten gegenüber entschuldigen seinen leichtsinn. Es ist etwas gewaltiges nötig, ihn aus dem strudel, in dem er dahintreibt, herauszureifsen. Und obwohl diese veranlassung - das verspielen des bildes - von aufsen kommt, liegt der umschwung 
in seinem innern. Es durchrüttelt ihn ein schrecken, der ihn fast zu einem verbrechen treibt, ihm aber die augen öffnet. Es ist der dichterin durchaus gelungen, seine besserung glaubhaft $\mathrm{zu}$ machen. - Nicht weniger sympathisch erscheint Angelica, das innig liebende und doch stolze mädchen, das dem so oft verlorenen, wieder einmal zurückgewonnenen geliebten einen talisman mitzugeben beschliefst. Wer möchte es ihr verdenken, dafs sie schliefslich allem vorsatz zum trotz den geliebten, der bei aufrichtiger zerknirschung einen gewissen stolzen mut nicht verleugnet, verzeihend zurückruft? - Diese handlung hat einen glücklichen reflex in einer weniger ausführlichen nebenhandlung. Lady Wealthy gerät in ihrer eitelkeit und gefallsucht in eine peinliche lage. Ihr brief an Valere stellt sie arg blofs. Dals diese verbindung der haupt- mit der nebenhandlung dazu dient, die wackere gesinnung Valeres zu zeigen, ist sehr glücklich. - Auch Lady Wealthy verbirgt unter dem fehler der eitelkeit, zu der sie, die junge hübsche witwe, die schmeichelnde huldigung der herren treiben mag, einen gesunden kern. Das zeigt schon ihr verhalten dem Marquis of Hazard gegenüber. Auch sie bedarf einer aufrüttelung, um den weg der vernunft zı erkennen.

Man findet bei Mrs. Centlivre eine eigentümlichkeit der entwicklung darin, daIs in aufeinanderfolgenden stücken eine figur entsteht, sich ausbildet, einen höhepunkt erreicht und wieder verlälst. In dieser beziehung steht in G. der diener auf dem höhepunkt der entwicklung. In L.C. ist Martin der nachäffer seines ehemaligen herrn, in St. H. Rosco, ein abklatsch von seinem niedrig denkenden herrn, Hector ist in vielen stücken der dienende freund Valeres (s. die charakteristik in der gen. diss.). - Die sprache ist frisch und charakteristisch, die dialogführung flott. Es ist ein recht erfreuliches stück, ein lustspiel im besten sinne des wortes!

Nun wird als quelle dieses stückes Regnards Le Ioueur angegeben (s. Grober: Das Verhältnis von S. Centlivre's Lustspiel The Gamester zu Regnard's Lustspiel Le Ioueur. Diss. Halle 1900; Hohrmann in dem oben genannten aufsatz). Mit spannung sieht man der entscheidung entgegen, ob nicht alles wesentliche aus der vorlage stammt. Und was zeigt sich? Gemeinsam ist, dals ein spieler auftritt, dafs er in häufiger 
geldverlegenheit ist, dals sein vater die heirat des sohnes wünscht, dals das von ihm geliebte mädchen eine schwester hat, die den spieler zu umgarnen sucht, dafs ein hochstapelnder marquis auftritt, der diese schwester umwirbt, dafs die geliebte dem spieler ihr bild schenkt, dafs der onkel des spielers jene umwirbt. - Doch ist der sinn des französischen stückes nun der: der spieler zeigt sich unwürdig der liebe des mädchens; das bild hat er verpfändet, der onkel hat es erworben. Am schlufs des stückes sagt das mädchen:

"Quiconque a mon portrait, sans crainte de rival,

"Doit avec la copie avoir l'original.

So heiratet der onkel das mädchen; der spieler tröstet sich mit dem spiel und zieht von dannen. - Das stïck predigt also die banale weisheit: Seht, so ein spieler ist unverbesserlich. Alles, was an dem englischen lustspiel zu loben ist, stammt von den änderungen. Dieses stück spricht: die macht echter liebe überwindet alle anderen leidenschaften. - Grober sagt s. 22 von der spielerszene: "So endet diese äufserst wirkungsvolle szene. Sie ist vollständig originell und eine der gelungensten des ganzen stückes. Kann man doch hier - und das war für S.C. mit der hauptgrund für ihre einführung - den spieler in seiner vollen tätigkeit sehen, während man ihn im Ioueur und vorher im Gamester nur vom hörensagen kennen lernt." Das ist richtig, trifft aber noch nicht den nagel auf den kopf. Was diese szene so vorzüglich macht, ist die teilnahme an der leidenschaft, die vorbedingung dafür, dafs wir Valere entschuldigen, dals Angelica ihm verzeiht. Hier liegt der höhepunkt des kampfes zwischen liebe und leidenschaft. Ohne leidenschaft versetzte er nicht das bild, ohne liebe brächte ihn der verlust nicht zum rasen. Die verzweiflung, die ihn beinahe zum mord treibt, zu zeigen, war ein ungemein geschickter griff, um die besserung des spielers glaubhaft erscheinen zu lassen. - Dals Angelica selbst ihm das bild abnimmt, hat in dem motiv der verkleidung etwas geschmackloses; aber auf der andern seite liegt etwas zartes gerade darin, dals das bild nicht in fremde hände kommt; und dafs Angelica selbst eingreift, dient der einheitlichkeit. - Was die charaktere anlangt, so ist die rolle des Marquis bei Regnard besser durchgeführt als bei $\mathrm{S}$. Centlivre. Das würde bei ihrer nebensächlichkeit nicht ins gewicht fallen, 
wenn nicht auch hier die dichterin nach dem schlufs der handlung noch eine lange szene einfügte, die der entlarvung jenes hochstaplers dient; - übrigens ist diese figur aus patriotischen gründen in einen ausländer verwandelt. - Dorantes charakter ist gänzlich verändert, Hector ist wieder übernommen; seine sorgende treue ist aber weit mehr hervorgehoben. Lovewell und Betty sind ganz neu erfunden; auf jenen sind züge des Regnard'schen Dorante übertragen. Wenn Grober sagt: "Die Lady Wealthy ist in G. eine dame, die den Valere aufrichtig liebt ...", so ist das ein irrtum. Hohrmann nennt sie richtiger eitel, gefallsüchtig. Sie hat nach koketter weiber art den wunsch, den hübschen, von anderen begehrten mann für sich zu gewinnen; gerade dieser charakter ist von Regnard sehr treu übernommen. Favourite ist ebenfalls von Grober nicht erkannt, sie ist nicht "ihrer herrin treu und immer auf deren vorteil bedacht", sondern sie ist bestechlich; dafs sie so ist, ist aber sehr glücklich, denn die siegreiche liebe feiert nur einen triumph mehr.

Es bleibt noch ein wort über die gedanken und grundsätze, die in bezug auf die spielerleidenschaft in G. so reichlich vorhanden sind, zu sagen. Hohrmann führt die wörtlichen übereinstimmungen beider stücke an; es ist nicht eine der im zweiten teil unserer arbeit (s. Anglia N. F. XX s. 474 ff.) genannten tendenzen darunter. Hohrmann fügt hinzu: "Von diesen wenigen kurzen stellen abgesehen, hat die Engländerin den übernommenen stoff mit eigenen worten zum ausdruck gebracht."

$\mathrm{Zu}$ diesem stück hat Lessings Minna von Barnhelm manche beziehungen. Auf eine weist Erich Schmidt (Lessing, 2. aufl., I, 475) hin; sie betrifft den hochstapler, der bei Lessing Franzose ist, hier es zu sein vorgibt. Es kommen noch hinzu: das innig liebende mädchen, der zahlungsunfähige herr, der treue diener, der die rechnung aufzustellen hat, schliefslich der spieler (Cogdie), der in einer art gutmütigkeit das falschspielen lehren will. Diese motive lagen in dem damaligen englischen lustspiel, in dessen zeit Lessings stück seine wurzeln hat, herum, und man darf keine $\mathrm{zu}$ weitgehenden schlüsse daraus ziehen (s. Schmidt, a. a. 0., s. 465). - Lessing hat den besseren, weil gröfseren hintergrund; in der kraft der charakteristik steht ihm Mrs. Centlivre wohl nicht nach. 
Hätte diese dichterin nichts als G. geschrieben, so würde ihr der ruf hoher dramatischer fähigkeit bereits gesichert sein.

Mit dem nun folgenden stück schreitet sie auf dem in B. D. betretenen pfade weiter, der aber bereits abwärts führt. Eine quelle für B. T. ist nicht bekannt. Die ersten szenen erinnern nach Hohrmann an eine szene in Le Divorce von Regnard, wo ein bejahrter gatte seiner jungen frau lebhafte vorwürfe ohne jeden erfolg macht; auch dals die frau von einem kammermädchen unterstützt wird, fehlt nicht. Ein teil der quellenfrage erledigt sich zweifellos durch die engen beziehungen dieses stückes zu G. Das thema der nebenhandlung in G. wird hier zum hauptthema: der gute ruf der frau ist nichts nebensächliches. Es ist mit pedantischem nachdruck häufig wiederholt. - Auch sonst sind die beziehungen zwischen beiden stücken zahlreich. Das spielermilieu, selbst die spielerszene mit dem ausbruch der leidenschaft, kehren wieder. Lovewell erscheint in Lord Worthy, der lebemann in Sir James Courtly, der würdige vater in Sir Richard Plainman wieder. Man kann Lady Reveller als eine nachfolgerin sowohl Valeres als auch der Lady Wealthy ansehen. Mit dieser verbindet sie aufser eitelkeit und gefallsucht die gefahr, in die ihr ruf kommt, mit jenem die spielleidenschaft. Ihr charakter ist allerdings weniger sympathisch als der des helden in G. Ist schon ihr mundwerk dem würdigen onkel gegenüber etwas sehr lose, so ist man auch einer dame eine art hochstapelei weniger zu verzeihen geneigt, als leichtsinn einem jungen mann. Das schlimme ist nämlich, dafs es die schöne witwe darauf absieht, zahlungsfähige leute an ihren spieltisch $\mathrm{zu}$ ziehen, so bedenklich sie auch sonst sind. So erzählt wenigstens ihr onkel. Wir selbst sind zeugen, dafs der Mrs. Sago ihr geld und ihre dummheit, dem kapitän Hearty die annahme, dafs er selbst falschspielenden damen gegenüber ritterlich sein müsse, diesen zutritt verschaffen. In des letzteren zornesausbruch über die unordnung des spiels liegt etwas ungemein realistisches. Aber die verwöhnten damen sind nur schockiert von dieser verbindung von rechtlichkeit und roheit. Da holt Sir James zu einem wohlberechneten schlage gegen Lady Reveller aus. Ihm, dem menschenkenner, hat Lord Worthy, der, etwas weltfremd, ein willenloses spielzeug seiner liebe ist, leid getan. Die anschaulichkeit der belehrung be- 
wirkt bei der dame, was die blofsen worte nicht vermochten. Die heilung erinnert sehr an die der Lady Wealthy. - Das stück hat zwei nebenhandlungen, von denen die eine, die Lady Lucy betrifft, einer inneren verbindung mit der haupthandlung nicht entbehrt. Lucy ist der offenbar bewufst geschaffene gegensatz zu Lady Reveller. Die andre handlung aber fällt ganz aus dem rahmen und ist in sich nicht folgerichtig. Denn was haben die erziehungsgrundsätze, die Sir Richard Plainman im ersten akt äufsert, mit dem erziehungsergebnis zu tun, das uns in Valeria entgegentritt? - Zugleich aber hält leider das element der possenmotive verstärkt seinen einzug. Lovely wird bei Valeria überrascht, er kriecht unter ein fals und wird dort entdeckt. Bald wird das gebiet, dem solche scherze angehören, sich erweitern.

Fast sieht es aus, als ob das nun folgende stück der mit den beiden vorhergehenden eingeschlagenen richtung treu bleiben wollte. Wird doch in Belair, dem helden von L. V., ein Don Juan ins ehejoch gefesselt, und liegt der gedanke doch nahe, eine solche umwandlung in einer charakterentwicklung zu suchen. Doch hat der dichterin eine solche absicht leider ferngelegen. Denn Belair ist nach seiner bekanntschaft mit Camilla ein weiberjäger geblieben. Mit anderen worten: von der charakterkomödie geht Mrs. Centlivre zur intriguenkomödie über. Die charakterdarstellung leidet dabei indessen keinen schaden. Die dichterin ist schon so gewandt, dals sie die gewonnenen erfahrungen auch anzubringen versteht, wenn sie ein neues feld betritt. Daher ist L. V. kein ungeschicktes stück geworden. Der schwerenöter, der sich mit nie versagender unverschämtheit aus den schwierigsten lagen heraushilft, ist nicht übel. - Eine gröfsere ähnlichkeit mit der tendenz der vorhergehenden stücke zeigt die figur der Lady Cautious. Auch sie hat, wie Lady Wealthy und Lady Reveller, nicht übel lust, sich über die engen schranken der sitte hinwegzusetzen, und wird durch eine schlimme erfahrung belehrt, in welcher gefahr sie sich befindet.

Die quelle für die haupthandlung ist in Th. Corneille's Le Galant Doublé zu suchen (s. Hobohm, das Verhältnis von Sus. Centlivre's Love at a Venture zu Th. Corneille's Le Galant Doublé. Diss. Halle 1900). - Gemeinsam mit der quelle ist das abenteuer eines helden, der zwei damen zugleich den hof 
macht und sich ihnen unter verändertem namen nähert. Eine genauere nachdichtung der vorlage ist dabei die eingangsszene des ersten aktes, der anfang der szene Belair-Patch, aus dem zweiten akt das erste zusammentreffen Belairs mit den beiden mädchen, aus dem dritten akt eine unterhandlung Belairs mit Robin, aus dem vierten akt ein selbstgespräch Robins am eingang, die verhaftungsszene, einige züge aus der unterhandlung Revels mit den beiden mädchen, ein kurzes gespräch Belairs mit Robin, aus dem fünften akt nur das auftreten Positives, des vaters Camillas. - Der held hat in beiden stücken einen freund.

Alles andre ist selbständig, und gerade die besten züge sind hinzugefügt, insbesondre der wirkungsvolle umstand, dafs Sir William Camilla liebt und die freunde dadurch nebenbuhler werden, ferner das drollige einmischen Robins, die psychologisch interessante unterhaltung der mädchen über den bewerber. Glücklich geändert ist, daIs der held sich nicht, wie bei Corneille, wegen eines mordes auf der flucht befindet, dals er nicht viermal, sondern blofs zweimal bei den mädchen erscheint, dafs nicht - wie es bei Corneille fortwährend geschieht - ein mädchen allein die prüfung vornimmt, daIs Revel nicht aus dem gefängnis zurückkehrt, sondern nach seiner verhaftung ein für allemal verschwunden ist. - Was die charaktere anbetrifft, so sagt Hobohm: "Sehen wir bei Th. Corneille blutlose, monotone gestalten, so kennzeichnen sich die der Mrs. Centlivre durch frische lebendigkeit und echte fröhlichkeit. - Die vorlage Belairs, des totverachtenden kämpfers, des treuen freundes, ist ein wegen mordes flüchtiger mädchenjäger, die vorlage Sir Williams eine gänzlich farblose figur. Gegen Robin ist der französische diener nur ein schatten. Camilla ist idealer, Beliza nicht so matt wie die vorlage."

Hohrmann erinnert noch daran, dafs in Molière's Avare Valère die bekanntschaft der jungen Elise, der tochter Harpagons, macht, indem er ihr das leben rettet.

Welches das vorbild des Sir Paul Cautious ist, erscheint fraglich; Hobohm findet mit Molière's Avare, Hohrmann mit dem Malade imaginaire ähnlichkeiten heraus, ein gutes zeichen für die relative selbständigkeit jener figur, die psychologische feinheiten einer art besitzt, die sonst unserer dichterin nicht 
eigen ist. Zum beweise sei folgende bemerkenswerte stelle angeführt:

\section{"Enter Sir Paul with a Candle.}

Sir Paul: Merry on me, what a Noise is here in this House - Adsbud, it were a Blessing to be deaf - what did I say Heaven forgive me - if I should be struck deaf now, what a lamentable Thing 'twou'd be - humph - ha - in my Conscience, my Ears sing, I have a strange Humming in my Head - pray, Heaven, I grow not deaf in earnest"; - dann denkt er an die kosten, die die vielen besuche seiner frau verursachen; er werde noch gänzlich verarmen; - "I may thank Marriage for it - if I shou'd come to be maintain'd by the Parish now - Oh sad - Oh, sad - or shou'd live to be blind - and led with a Dog and a Bell - what shall I do, if I come to that, and who knows but I may - Let me see, let me see, I'll try how I can walk in the Dark (Puts out the Candle)."

Die Wou'dbe-gestalt erinnert Hobohm an Ben Jonson's The Divell is an Asse; von eigentlicher beeinflussung könne keine rede sein. Hohrmann findet einzelne züge bei Molière wieder. Auch hier also ist eine bestimmte vorlage wohl nicht anzunehmen.

Schliefslich sei noch ein sehr richtiges ergebnis Hobohms angeführt: die sprache der Engländerin ist frisch, die des Franzosen lau.

Das stück hat den vorzug der einheitlichkeit, wenn man von dem auftreten von nebenpersonen absieht; denn Belair ist durchaus der mittelpunkt des ganzen. Aber auch hier findet man jenes merkwürdige unverständnis für dramatische entwicklung. Es stellt sich nämlich heraus, dals das mädchen, um das der held fünf akte hindurch kämpft, weil er der väterlichen beeinflussung zuvorkommen will, eben die braut ist, die der vater ihm bestimmt hat.

L. V. wurde von Colley Cibber am Drury Lane-theater zurückgewiesen und in Bath gespielt. Der prolog spielt auf dieses schicksal des stïckes an, vielleicht auch der titel. Das verhalten Cibbers erscheint deshalb in einem nicht ganz schönen licht, weil sein Double Gallant eine kompilation aus L. V., the Lady's Visiting Day und the Reformed Wife 
(Burnaby) ist (s. Besser, Colley Cibbers Double Galant und seine Quellen, Diss. Halle 1903).

Mit L. V. ist Mrs. Centlivre an das ende einer entwickelung gelangt, die dem gebiete der charakterkomödie angehört. Es hatte sich darum gehandelt, umwandlungen im charakter darzustellen, noch genauer, irrungen und schwächen des charakters aufzuheben. Den höhepunkt dieser gruppe bildet G. Die tendenz findet sich schon in der Doubtful-gestalt von L. C. und in der Carefull-gestalt in B. D. Es folgt ein etwas weniger glücklicher versuch in B. T. In L. V. spielt die intrigue schon eine breite rolle, aber der gedanke an die veränderungs-, bezw. verbesserungsfähigkeit des charakters blickt noch durch. - Mit PI. L. hört diese richtung auf. Das interesse ruht auf verkleidungs- und überraschungsmotiven; wir befinden uns auf dem gebiet der posse. - Die idee des stückes soll sich nach einer äufserung des ersten aktes als der versuch einer liebenden darstellen, die nebenbuhlerinnen zu verscheuchen, ohne selbst erkannt zu werden. Gerade jenes ziel wird aber nicht erreicht. Denn wenn sich nicht am schlufs herausstellte, dafs Lucinda die schwester Belvils ist, wären alle listen umsonst gewesen, und da es sich herausstellt, sind sie unnötig gewesen. Ein unerwarteter gewinn ist für Isabella abgefallen: sie ist in ihrer verkleidung als landmädchen zeugin einer liebeserklärung gewesen, die Charles der Lucinda macht, so dals sie daraus hoffnung schöpfen kann, dals jener in die lösung des väterlichen kontraktes, der sie an ihn bindet, willigen wird. - Erweist sich die lebhafte tätigkeit Isabellas als ziemlich zwecklos, so ist das verhältnis Belvils zu Lucinda nicht ergiebiger. Macht er doch die fünf akte hindurch einer dame den hof, die schliefslich beiseite gestellt werden mufs. - Die platonische dame, auf die der titel hinweist, ist Lucinda; sie zeigt eigenschaften, die jenen namen rechtfertigen, nur im ersten akt. Später benimmt sie sich ganz wie andre mädchen, die sich verlieben, eifersüchtig werden, schmollen und sich wieder versöhnen lassen. Leider ist die quelle nicht bekannt. Man könnte (eben nur nach dem ersten akt) fast auf den gedanken kommen, dal's der herkunft des stückes das problem zu grunde liegt, dafs das schwesterliche verhältnis auch, wo es verhüllt ist, sich in natürlicher abneigung gegen sinnliche liebe zeigt. - Einige beziehungen dieses stückes zu fran- 
zösischen komödien hat Hohrmann herausgefunden. Die erste szene (Tally und sein diener) ist eine getreue nachbildung der ersten szene des Regnard'schen einakters: Attendez-moi sous l'orme. Was sich in der Dowdy-szene des dritten aktes (s. in der diss. episode 2) an "The Elements of Toylet" anschliefst, ist ebenfalls aus dem genannten stück (sz.6); "an einzelnen stellen steigert sich die abhängigkeit zur übersetzung". - H. weist auch auf eine reihe von ähnlichkeiten zwischen Mrs. Dowdy und Jourdain im Bourgeois gentilhomme hin.

Berührungspunkte mit dem vorhergehenden stück sind in den hauptpersonen vorhanden. Der Don Juan erscheint in Belvil wieder, aber phlegmatischer als in Belair. Dieser typus ist also im abnehmen begriffen. Ein anderer, nämlich der komische, nimmt zu. An stelle Wou'dbes tritt die Dowdy, die eine geschickt geschaffene figur ist. Dieses spafshafte element macht sich bald noch breiter, und zwar mit gröIstem erfolg. In L. V. hing Wou'dbe mit der handlung gar nicht zusammen, Mrs. Dowdy in Pl.L. hatte einen, wenn auch nur passiven einflufs. Wir kommen nun zu einem stück, in dem der komische typus die hauptrolle spielt, obwohl sein vertreter nichts weiter tut als die eigentlichen handlungen fortwährend zu stören. Es ist der wohlbekannte Marplot, der held von B. B., der Busy-body selbst.

Eine gesellschaft, der der berühmte Betterton angehörte, spielte 1708/9 im Drury-Lane-theater. ${ }^{1)}$ "The only success of this season was achieved by Mrs. Centlivre's 'Busy Body'." - Die rolle des helden wurde von Pack gespielt, der später auch die des dieners Lissardo in W.S. kreierte. Als das stück den spielern angeboten wurde, hatte niemand vertrauen dazu. Der schauspieler Wilks, der die rolle des Sir George spielte, erklärte, 1) "that not only would it be 'damned', but that the author of it could hardly expect to avoid a similar destiny, and yet its triumph was undoubted, though cumulative." Genest glaubt diese geschichte einfach nicht und gibt in der Biogr. dram. an, dafs dieser ausdruck bei B. Str. fiel, wo er übrigens auch nicht ain platze gewesen wäre.

1) Doran I, 311 und 244. 
Das stück ist von Joh. Friedrich Jünger unter dem titel "Er mengt sich in Alles" frei ins Deutsche übertragen.

Über die quelle gibt es eine arbeit von Weidler (Das Verhältnis von Mrs. Centlivre's The Busy Body zu Molière's L'Etourdi und Ben Jonson's The Divell is an Ass. Diss. Halle 1900). - Nur eine der beiden handlungen ist mit Molières stück verwandt, nämlich die von Sir George und Miranda getragene. Doch ist schon hier die verwandtschaft sehr lose. Die abhängigkeit läfst sich nur durch allerhand künstliche verschiebungen belegen, indem von der einen person auf eine andre, der jene sonst gar nicht entspricht, züge übertragen gedacht werden. Hohrmann geht daher in seiner guten arbeit auf eine beziehung zwischen diesen beiden stücken überhaupt nicht ein. Wir glauben, dafs allenfalls eine ferne anregung, nicht eine nachweisbare beeinflussung vorliegt. - Es sei aber festgestellt, dals Weidler zu dem schlufs kommt, dafs der aufbau bei der Engländerin viel geschickter ist als bei Molière.

Die szene, in der Miranda die stumme rolle spielt, ist Ben Jonson nachgebildet und "geschickt in das stück verflochten."

B. B. hat in der figur Marplots seine einheitlichkeit. Dals zwei handlungen neben einander herlaufen, ist bei diesem stück ein vorteil. Denn dadurch erst wird das täppische hinundhertorkeln jenes komischen gesellen recht charakteristisch. Im übrigen sei auf die ausführliche charakteristik in meiner diss. (s. $28 \mathrm{ff}$.) verwiesen.

Das nun folgende stück M. b. ist mit beziehung auf die einheit ein arger rückschritt. Es hat im grunde genommen drei handlungen, die nichts mit einander zu tun haben. Es wurde nach seinem vorwort zu urteilen, zunächst mit erfolg gespielt, aber doch bald vom spielplan abgesetzt. Mrs. Centlivre schreibt das boshaften intriguen zu: "Now, by the Rules of the House it ought to have been play'd on: But who can secure the Life of a Play, when that of a Man is often sacrificed to the Malice of Parties?" Auch sonst spricht aus dem vorwort grolse bitterkeit. Es redet von einem artikel im Female Tatler, der böses blut gemacht hatte und dessen autorschaft man der dichterin zuschrieb. Sie lehnt diesen verdacht aber mit nachdruck $a b$.

Die routine der geübten bühnenschriftstellerin verleugnet sich in diesem stücke trotz des oben gerügten fehlers nicht. 
Indessen wird sich zeigen, dafs sie sich die arbeit nicht allzu schwer gemacht hat.

Die erste handlung stammt aus dem einakter Le Deuil von Hauteroche (La Haye. 1682). Ein sohn (Timante $=$ Constant) lügt dem gutsverwalter (Jaquelin $=$ Trusty) seines vaters (Pirante $=$ Sir Jeffrey) vor, dieser sei gestorben. Er nimmt ihm als der nunmehrige erbe eine gröfsere summe geldes ab. Der vater trifft bald darauf ein, wird zuerst für einen geist gehalten, dann erkannt. - Die entlehnungen sind zahlreich und vielfach wörtlich, so weit eine übertragung von versen in prosa das verträgt. Doch gerade bei genauem vergleich fällt die selbständigkeit des denkens der Mrs. Centlivre auf. Oft beruht der unterschied nur in einer nüance. Die gröfsere kraft, realistik und anschaulichkeit, ja die tiefere lebensauffassung und lebenswahrheit sind auf ihrer seite. - Es sei das an zwei beispielen bewiesen. Der Franzose sagt, die farbe der trauer könne bisweilen das herz erfreuen,

..., quant un Mary fait enterrer sa Femme.

Comme en se mariant on se met en Danger

D'avoir pendant ce nœud tout le temps d'enrager,

Je croy que pour guerir cette sorte de rage,

Il n'est rien de meilleur qu'un prompt et doux Veufvage . .

(Szene 1).

Er setzt also der unglücklichen ehe die freude über den etwaigen tod der frau entgegen. - Die entsprechende stelle in M. b. lautet: - "As when a Wife buries ber Husband, she has Sorrow in one Hand, and Ioy in t'other; a short Widowhood cures such a Grief." Das ist ein genrebildartiger reflex aus dem wirklichen leben, ein mit bitterem lächeln geäufserter gedanke an die notwendigkeit, sich mit dem tode abzufinden. Auch Constants verhalten bei dieser auseinandersetzung des dieners ist geschmackvoller als das Timantes. Jener hört wie nebenbei seinem meditierenden diener $z u$, dieser entwickelt die gedanken mit ihm. - Die zweite stelle betrifft das thema "geld". Mrs. Centlivre findet in der vorlage eine auslassung über den wert des geldes:

Puis qu'il a tant de bien, il est noble de reste:

\section{Peste,}

Combien de soy-disans Chevaliers et Marquis,

Se targuent sottement de Noblesse à Paris, 
Dont en s'emmarquisant la plus haute Noblesse,

A seulement pour Titre une grande richesse,

Sans cela leur naissance est Basse et sans éclat,

Et leur bien en un mot, fait tont leur Marquisât:

Ces Gens au temps qui court ont beaucoup de Confrères;

Diese auf enge pariser lebemannsverhältnisse zugeschnittenen gedanken werden $\mathrm{zu}$ der vielseitigen und eindringlichen, aber auch bitteren lobpreisung des geldes, ${ }^{1}$ ) die oben schon angeführt ist. - Ähnliches liefse sich von der wuchtigen satire auf die "feinen herrn" beweisen, die Roger in den mund gelegt ist (s. Anglia. N. F. XX; s. 473 ff.). - M. b. enthält überhaupt viel bittere kritik sozialer verhältnisse, die der quelle ganz fern liegt.

Einige einzelheiten, die Crispin, die schwächere vorlage des dieners Clinch, sagt, sind in M. b. der prachtvoll-derben gestalt Rogers in den mund gelegt. Dieser ist der freier Dorothys. Auch deren charakter ist gegen die vorlage gehoben, wo Perrette, die dienstmagd Jaquemins, vor allen dingen freigebigkeit $z \mathfrak{u}$ schätzen weifs. Auch Perrette hat einen bewerber, der gegen Roger blutleer erscheint. - Manche züge Crispins sind statt auf Clinch auf Lovely, den freund Constants übergegangen; so insbesondere die vermittlung bei dem feilschen mit dem verwalter, die auch besser für ihn als für den diener palst.

Constants hauptzweck bei seiner recht wenig zartfühlenden list ist aber - und das ist der springende punkt bei dem vergleich - ein wesentlich anderer als der Timantes. Dieser benutzt zwar die gelegenheit, die tochter zu entführen; geheiratet aber hat er sie, merkwürdig genug, heimlich schon ein halbes jahr vorher. Der eigentliche gewinn, den er erwartet, ist nur das geld. - Bei Constant aber ist das lebensglück in gefahr. Sein vater hat ihm eine unausstehliche person, Mrs. Homebred, angetragen; er aber liebt Belinda, die er nunmehr durch diese list gewinnen will. Wiederholt spricht er seinen widerwillen gegen die heuchelei aus, zu der er gezwungen ist; und zum erstannen seines dieners versichert er, dals ihm an dem mädchen mehr liege als am geld. - Dieses nimmt er als

1) S. Anglia. N F. XX; s. 479 ff. 
praktischer mann allerdings als abschlagszahlung auf die mitgift und das erbe mit.

Der alte Pirante findet sich, wie sein sohn übrigens erwartet hat, in das unabänderliche. Der alte Sir Jeffrey, urwüchsiger, aber unliebenswürdiger als sein vorbild, wütet, bis er hört, dafs Belinda die tochter eines lords ist. Der grundsatz der ebenbürtigkeit ist gewahrt; hier siegt also nicht die liebe, sondern die engherzigkeit der Mrs. Centlivre. Diese geschmacklosigkeit begeht Hauteroche nicht.

Für die geisterszene ist vieles wörtlich übernommen, aber verschoben und durch gröfsere realistik sehr drollig gestaltet. Bei der aufführung hatte man einen teil streichen wollen, die dichterin hat sich dem energisch widersetzt und mit recht.

Ward hebt die ähnlichkeit von M. b. mit Farquhar's The Beau's Stratagem, das einige jahre vorher erschien, hervor. Die gemeinschaftlichen züge sind gering: die stücke spielen nicht in London; die männlichen hauptspieler kommen eben von dort und leiden mangel an geld; in M. b. sind sie auf der reise überfallen worden (warum Mrs. C. dieses von ihr nicht weitergeführte motiv überhaupt aufnimmt, ist nicht recht klar), in B.'s Strat. steckt der wirt mit strafsenräubern unter einer decke; ein kirchgang spielt in beiden stücken eine rolle, in M. b. eine ganz nebensächliche unter ganz andern umständen; ein gespräch über liebe in B.'s Strat. (zwischen Archer und Cherry) erinnert an ähnliche gespräche zwischen Constant und Belinda, Lovely und Maria; das wirtstöchterchen bei F. glaubt, es fliefse edles blut in ihren adern, was an Belindas vornehme herkunft erinnert.

Auch für die zweite handlung ist die vorlage bekannt; es ist Regnards lustspiel Les Folies Amoureuses. Die anlehnung ist eng; änderungen sind nach der $^{1}$ ) seite der urwüchsigkeit vorgenommen; die kaffeehausszene und das zusammentreffen in der wohnung Watchums sind neu.

M. b. ist keins der besten stücke unsrer dichterin; es ist mit viel geschicklichkeit, aber mit wenig fleifs gearbeitet. Die errungenschaft der einheit ist wieder verloren gegangen. Auch sonst gleitet es aus der bahn, der sich die verfasserin zugewandt hatte, der beobachtung und schilderung von be-

1) Hohrmann sagt: "grobsinnlichen". 
sonderen charakteren. Denn die charaktere sind alltäglich. Die charakteristik ist entsprechend der flüchtigkeit der ganzen arbeit nicht immer folgerichtig durchgeführt.

Aber mit dem folgenden stück geht sie auf den vorher betretenen pfad zurück und hält sich fast zu sehr an derselben stelle. Bei B. B. war darauf hingewiesen, dals die doppelte handlung der in der Marplot-figur ruhenden einheit nicht schadet. Um dieses gleichmals herzustellen, bedurfte es grofsen dichterischen taktes, der ihr in $\mathbf{M}$. L. nicht mehr ganz zur verfügung steht. In der absicht, dieselben wirkungen wie in B. B. zu erzielen, hat sie vielfach zu stark aufgetragen. Das betrifft im wesentlichen die hauptfigur, auf deren eingehende besprechung in der diss. (s. $37 \mathrm{ff}$.) wir verweisen müssen. - Quellen für die handlungen sind nicht bekannt. Beziehungen $\mathrm{zu}$ früheren stücken findet man mehrfach. Mad. Joneton erinnert an Lady Reveller in B. T., an Lady Wealthy in G., ist aber überspannter und weniger natürlich. Dals ein weibliches wesen einen mann entflammt, bei dessen freund aber fast widerwillen erregt, kam mit bezug auf Miranda in B. B. vor, die ehebrecherin kehrt aus L. V. wieder.

Etwas zerfahrenheit zeigt die intrigue Ravelins mit Marton; obwohl die Joneton beide beim Tête-à-Tête überrascht, ändert das nichts an ihrer stimmung gegenüber Ravelin.

Mit M. L. ist die richtung, der es angehört, erschöpft. Sie hatte in B. B. den höhepunkt erreicht. Der schlechthin komische charakter verschwindet ganz und die originale fähigkeit der dichterin schläft auf einige jahre. Sie füllt die pause mit einem intriguenstück aus.

In dem vorwort zu P. L. entschuldigt sich die dichterin, dals das stück an den beiden aufführungstagen ohne epilog gespielt worden sei. Dieser epilog, eine verherrlichung Marlboroughs, habe am ersten tage die lizenz nicht erhalten. Am zweiten tage aber sei die schauspielerin, die ihn sprechen sollte, durch drohbriefe gewarnt worden, diesen ausdruck whiggistischer begeisterung vorzutragen, und habe sich daher geweigert.

Das stück war nicht sehr erfolgreich; schon am ersten abend wurde am schlufs gezischt, ein zeichen des mifsfallens, das Mrs. Centlivre eben dem fehlen des epilogs zuschreibt. - 
Andre scheinen andrer ansicht gewesen zu sein; denn sie gibt im vorwort $\mathrm{zu}$, dals die nachtszenen dem geschmack der Engländer wohl nicht zusagen mögen. Auch bekennt sie, sich wenig mühe mit dem stück gegeben zu haben, dessen wesentlicher teil aus einer spanischen komödie, die sie aber nicht nennt, stamme.

Die anlage des stückes ist nicht ungünstig. Denn da Camilla und Constantia eng befreundet sind, die energische Camilla aber die not der anderen mitempfindet, andrerseits sich ihrer macht über Belvil wohl bewufst ist, so hätte sie ja diese macht mit nachdruck in den dienst der freundin stellen können. Scheint es doch so, als sie sagt (I, 264): "... whilst I have Power to charm your Brother, you shall not want a Friend to fend that Blow - I never will be his, till thou art happy." - Doch gleich darauf wendet sich das stück von Belvils widerstand gegen seiner schwester heirat ab und behandelt fünf akte hindurch die anschläge des lords, der der kandidat des vaters ist. Dieser vater aber hat solche furcht vor seinen sohn, dals er ihm seine absicht anfangs gar nicht zu verraten wagt. Trotzdem macht gerade er mit seinem lord so viele umstände. - Des hitzigen Belvil widerstand wird aber überhaupt nicht durch einen in der handlung liegenden einflufs, sondern durch einen deus ex machina in gestalt eines briefes erledigt, der den verzicht seines heiratskandidaten meldet.

Doch hat das stück auch vorzüge. Im ersten akt besonders findet man zarte töne, manche charakternüance, die feines psychologisches verständnis verrät, und man kann nur bedauern, dals ein solcher anfang zu nichts besserem verwendet worden ist als zum sprung in das gebiet der allergewöhnlichsten verwechslungstricks. Die letzten akte schwelgen darin bis zum überdrufs.

Die charakteristik ${ }^{1}$ ) aber ist vorzüglich. Die figur Constantias zeigt eine grofse fähigkeit, die äufserungen der stimmung anzupassen, zärtlich, empört, ängstlich zu sein, ohne dafs der grundton verloren geht.

Das stück ist so eingerichtet, daIs die beiden handlungen

1) S. indessen die bemerkungen über charakteristik oben 8. $79 \mathrm{ff}$. 
einander bedingen, so dafs eine ziemliche einheitlichkeit zustande kommt.

Die einsicht in die schwächen von P. L. hatte bei der dichterin gute vorsätze gezeitigt. Sagt sie doch im vorwort: "... and if $I$ live $I$ will endeavour to make my Friends amends in the next." Sie hat wort gehalten. In W. S. verwendet sie ihre charakterisierungsgabe für die darstellung von liebe und kampf zweier personen sehr sympathischer art.

Dieses stück war ein schlager seiner saison und wird noch heutigen tages mit erfolg gegeben. Doran sagt (s. 331): "The Violante of Mrs. Oldfield and the Don Felix of Wilks were talked of in every coffee-house." Felix war eine lieblingsrolle Garricks, die er sich wählte, als er zum letzten mal auftrat.

Als quellen gelten: The Wrangling Lovers: Or the Invisible Mistress von Ravenscroft, London, 1677 und Elvira von Digby, London, 1667.

Vorausgeschickt sei, dafs von dem hübschen grundgedanken, ein liebendes und geliebtes mädchen in den konflikt $\mathbf{z w i s c h e n}$ verschwiegenheit der gefährdeten freundin gegenüber und den verdacht der untreue $\mathrm{zu}$ bringen, in den vorlagen keine spur vorhanden ist.

Die hauptpersonen von The Wrangling Lovers sind Don Diego und Octavia; sie entsprechen Felix und Violante in W. S.; das paar Don Gusman und Elvira entspricht dem paar Colonel Britton und Donna Isabella. - In beiden stücken kommt noch ein freund und gastfreund (Don Ruis = Frederick) hinzu. Während dieser in Wr. L. neben Diego um Octavia wirbt, um schliefslich, dem schiedsspruch der dame sich fügend, überflüssig zu sein, ist Frederick die rolle des beraters und freundes zugewiesen; als solcher bildet er einen glücklichen gegensatz zu den liebhabern. - Don Ruis ist der bruder Elviras, deren vater überhaupt nicht erwähnt ist. Von einem konflikt wie dem Isabellas ist bei ihr nicht die rede. Octavias vater Count de Benevent ist ein mit dem schwert fuchtelnder narr.

Die handlung in Wr. L. verläuft folgendermalsen: Don Diego hat bemerkt, dals seiner geliebten der diener Gusmans nachgeht, um ihre wohnung zu erkunden, dals ihr in der nacht zu ihrem geburtstag ein andrer - er vermutet wieder 
Gusman - ein ständchen bringt, dals eben jener diener einen brief ins haus bringt, der auf das einverständnis der geliebten mit Don Gusman schliefsen lälst. - Die sache liegt aber so, dals im ersten fall der diener gar nicht Octavia, sondern einer andern dame nachgehen sollte, dal's das ständchen gar nicht von Don Gusman, sondern von seinem freunde Don Ruis herrührte, dals der brief gar nicht von Gusman, sondern von Ruis, und gar nicht an Octavia, sondern an deren zofe geschrieben war. - Nun hat Don Diego den diener, als er den brief abfalste, geprügelt; die freunde Gusman und Ruis überlegen sich die bedeutung dieser prügelei hin und her, und jeder kommt zu dem schlufs, er müsse Diego im duell töten. - Gusman kommt mit seiner forderung zuerst zum ziel und verabredet mit Diego den treffpunkt im walde. Aber Ruis hat achtgegeben, er folgt jenen mit freunden, kurz vor dem kampf erfolgt die aufklärung, und alles löst sich in frieden und freundschaft auf. Als Gusman vom kampfplatz zurückkehrend seine geliebte Elvira (Don Ruis' schwester) aufsuchen will, trifft er sie nicht zu haus, wird aber sofort in ihrem auftrage zu ihr geführt, und zwar durch eine hintertür zu Octavias haus und zimmer. Er trifft dort zunächst nur Elvira, beginnt aber seinen bericht so ungeschickt ("Don Diego is no longer my enemy nor your brother's"), dafs die im nebenzimmer horchende Octavia meint, ihr Diego sei tot, und herausstürzt. Die drei unterhalten sich noch, da kommt Octavias vater - er ist wütend, dafs er die hintertür offen gefunden hat - hinzu. Gusman flüchtet ins nebenzimmer. Der alte wird gefahrlos entfernt, da er sich erbietet, Elvira nach hause zu begleiten. Eben soll sich Gusman durch den vorderen ausgang entfernen, da der vater die hintertür verschlossen hat, als Diego erscheint. Gusman flüchtet wieder ins nebenzimmer, da kehrt der vater zurück. Diego will in jenes zimmer, Octavia reifst ihn zurück, aber er hat schon die grofsen fülse des hinter dem vorhang stehenden Gusman gesehen. Diego wird nun an die hintertür geführt, dort soll er warten, bis die zofe ihm öffne - den schlüssel hat man aus dem zimmer des alten schon wieder entwendet -; Gusman aber wird an das obere ende der treppe gestellt, wo er einen günstigen augenblick zum entwischen abwarten soll. Octavia geht hinunter, um des alten aufmerksamkeit abzulenken. Gusman entflieht; da kehrt Diego lauernd 
zurück, um den nebenbuhler zu erwischen, findet niemanden, der alte kommt tobend hinzu, weil er wieder das fehlen des schlüssels bemerkt hat, und greift Diego mit dem schwert an, der, sich verteidigend, langsam abgeht. - Unten wartet auf ihn Gusman und klärt ihm alles auf. - Warum hat er das nicht oben schon getan! er hätte viel verlegenheiten erspart!

Mrs. Centlivre hat sich durch dieses durcheinander von überraschungen und verwechslungen allerdings anregen lassen, hat aber das ganze auf eine viel bessere grundlage gestellt. Ihre Violante wahrt in dem geheimnis das glück der freundin, bei Ravenscroft dagegen bedürfte es nur rechtzeitig eines vernünftigen wortes, und fast alles wäre überflüssig.

Nun zur verschleierten dame! Elvira hat sich (vorfabel) in den bei ihrem bruder zu besuch weilenden Gusman verliebt, sie bestellt ihn $\mathrm{zu}$ einem stelldichein (I, 1), bei dem sie sich nicht entschleiert. Nachher aber wird er mit der nun unverschleierten Elvira durch ihren bruder bekannt gemacht und liebt nun diese (die identität beider kennt er ja nicht); der anderen annäherungsversuche weist er zurück. - Hierdurch hat sich Mrs. Centlivre $\mathrm{zu}$ dem stelldichein zwischen Isabella und Britton anregen lassen. Der schleier bleibt, alles andre ist verändert.

Als das duell (s. o.) bevorsteht, will Elvira, die für den geliebten und für den bruder fürchtet, Diego bitten, einige tage aus der stadt zu gehen; sie begibt sich verschleiert zu ihm. Da kommt Octavia hinzu, um die vorherigen mifsverständnisse aufzuklären. Die anwesenheit der verschleierten dame gibt ihrer eifersucht neue nahrung. - Die elemente dieser szene werden sowohl in der szene, wo Flora im kleiderschrank steckt, verwendet als auch in der anderen, wo Isabella vor Violante, Felix und Pedro geheimnisvoll durch das zimmer schreitet.

Schliefslich stammen auch der Algasil und seine leute aus der vorlage; mit ihnen verfolgt Count de Benevent seinen späteren schwiegersohn Diego, der gegen sein verbot sein haus betreten hat.

Noch könnten die beziehungen hier und da um eine vermehrt werden, aber immer wieder würden wir zu dem ergebnis gelangen, dals die verwendung der motive in ganz andrer anordnung und umgebung geschieht. Mrs. Centlivre hat die bausteine verwendet, aber ein anderes, besseres gebäude errichtet. 
Noch selbständiger erscheint die charakteristik. Die personen der vorlage sind trockne gestalten. Der kampf zwischen Felix und Violante dagegen liegt in ihren herzen. Zwar hat die eifersuchtsszene zwischen Octavia und Diego (akt 2) als vorlage für die schönste derartige szene in W.S. gedient; es sind sogar wörtliche entlehnungen vorhanden. Aber nicht entfernt reicht das vorbild an das ergebnis, für dessen reiz die folgende stelle angeführt sei:

"Felix: Now would I give one of my Eyes to be Friends with her; for something whispers to my Soul she is not guilty. - (He pauses, then pulls a Chair, and sits by her at a little Distance, looking at her some time without speaking - Then draws a little nearer to her) Give me your Hand at Parting, however, Violante, won't you (Here he lays his open upon her Knee several times) won't you - won't you - won't you!

Viol.: (Half regarding him) Won't I do what?

Fel.: You know what I would have, Violante. Oh, my Heart!

Viol.: (Smiling) I thought my Chains were easily broke (Lays her Hand into his).

Fel.: (Draws his Chair close to her, and kisses her Hand in a Rapture) Too well thou knowest thy Strength. - Ob my charming Angel, my Heart is all thy own. Forgive my hasty Passion; 'tis the Transport of a Love sincere!"

Es liegt etwas liebliches in dem kampf dieser beiden redlichen, verliebten, lebhaften jungen menschen.

Doran (a. a. 0. I. s. 190) macht darauf aufmerksam, dais von frau Centlivre noch ein zweites werk benutzt worden ist: Digbys Elvira (Elvira: Or the worst not always true. A Comedy. Written by a Person of Quality. London. 1667). Dieses stück ist in blankversen geschrieben. Sein inhalt ist folgender: Ein junger lebemann, Don Sancho, ist in das gemach eines mädchens, Donna Elvira, eingedrungen und dort entdeckt worden. Die ehre der jungen dame wird von ihrem geliebten, Don Fernando, schnell gerächt, der den gegner, ohne übrigens seinen namen zu kennen, schwer verwundet. Aber Elvira hat sich doch des geliebten verdacht und den zorn ihres vaters, Don Pedro, zugezogen. - Vor dem letzteren ist sie dann $\mathrm{zu}$ dem geliebten geflüchtet, der sie trotz 
seines argwohns nach Valencia in sicherheit bringt, wo er in Don Julio einen treuen freund besitzt. Bei dessen schwester wird Elvira als kammerfrau untergebracht, bis sich der verdacht kläre. Blancas geliebter indessen ist eben jener eindringling. Da nun dieser, von seiner verwundung geheilt, nach Valencia zurückkehrt, da die geliebte von seinen streichen schon gehört hat, - da ferner Don Pedro die spur der flüchtigen tochter verfolgt, wobei er Sancho statt Fernandos der entführung verdächtigt, da Blanca nichts von Elviras herkunft, Julio nichts von der liebschaft der schwester wissen darf, so sind für überraschungen, verwechslungen und verwicklungen reichlich unterlagen vorhanden. Die einzelheiten haben keine wesentlichen beziehungen zu W.S. Die lösung ist dadurch herbeigeführt, dals Sancho voller reue seiner geliebten beichtet, was er in Madrid übles angegeben hat, während die andern im versteck alles mit anhören. So stellt sich die unschuld Elviras heraus. - Dafs eines liebenden eifersucht erregt wird, ist also beiden stücken gemeinsam. Innerliche beziehungen sind auch durchaus nicht vorhanden. Digby, nämlich der Earl of Bristol, hat nicht einmal verständnis für die einheit der charaktere. So kommt es, dafs er den eifersüchtigen Fernando sich gewissermafsen überschlagen lälst, indem dieser plötzlich beschliefst, dem nebenbuhler die geliebte aufzudrängen. Eine solche ungeschicklichkeit begeht Mrs. Centlivre nicht. - Für eine vergleichung der übrigen charaktere läIst sich allenfalls durch verschiebung aller möglichen eigenschaften ein schwaches ergebnis erzielen. Die wackere Violante in W. S. hat in der schlaffen, klagenden Elvira wahrlich kein vorbild, ebensowenig die frische Isabella, so dals auch für diese figur nur äufserlichkeiten übernommen sind. - Eine so unsympathische und nicht einheitliche figur wie Don Sancho mit seiner liebe und seinem schurkenstreich hat Mrs. Centlivre nicht dargestellt. Ähnliches gilt von dem charakter seines dieners Chichon, der den streich seines herrn der geliebten verrät. - Am ehesten ist Don Lopez in W. S. mit Don Pedro in Elvira verwandt, die beide ihren töchtern harte väter sind. - An unwesentlichen einzelheiten bietet die vergleichung noch folgendes: der vorfabel der stücke gehört ein duell an, nach welchem der sieger sich verbergen muls, da der besiegte zu tode getroffen scheint; - ein freund leistet einem liebhaber dienste; - es 
tritt ein geschwisterpaar auf; - eine tochter entzieht sich dem willen des vaters durch die flucht; - Fernando hat mit Elvira einen augenblick den nämlichen plan wie Don Pedro in W.S. mit seiner tochter, nämlich sie ins kloster zu bringen; - der name Violante kommt in Elvira vor, und zwar für die nicht auftretende geliebte Julios. - Sobald man einer dieser beziehungen näher tritt, entfernen sich die stücke weit von einander. - Elvira ist ein im ganzen ungeschicktes machwerk mit schleppender handlung, ungeschickter diktion und elender charakteristik.

Keinen geringeren erfolg als W.S. hatte das nun folgende stück, B. Str.; Doran sagt mit bezug auf den Winter 1717/18 (I, s. 351): "The piece of this season which had stuff in it to cause it to live to our own times, was Mrs. Centlivre's Bold Stroke for a Wife. .... The Bold Stroke laught at and denounced by Wilks, and taken reluctantly in hand by the actors, is a fair specimen of that lighter comedy which borders upon farce, but in which the fun is genuine and the incidents not so improbable but that they may be accepted, or by the rapidity of their succession, laughed at and forgotten." - Die stolze ankündigung:

"To Night we come upon a bold Design,

"To try to please without one borrow'd Line. ")

hat der dichterin insofern geschadet, als daraus vielfach ihre unselbständigkeit in allen andern stücken gefolgert wird. Erfunden hat sie übrigens nur die grundhandlung, auf die es bei der beurteilung der selbständigkeit vielfach am wenigsten ankommt.

Gröfsere als Mrs. Centlivre würden als unselbständig gelten müssen, wenn man ihnen aus der entlehnung des rohstoffes einen vorwurf machen wollte. - Auch ganz wörtlich aufgefalst, ist ihre versicherung vielleicht wahr.

So selbständig nun die fabel des stückes auch ist, so weit entfernt sie sich von der wahrscheinlichkeit: ein mädchen er-

1) Die von Owen Williams (British Theatre, 2nd Ed., Leipsic 1831; s. dort A Bold Stroke s. 209 ff.) gemachte angabe, Mrs. Centlivre lehne sich mit diesem stück an Mottley an, ist nicht richtig. Die abhängigkeit ist umgekehrt. 
hält vier vormünder! Nicht neu sind die motive; verkleidung, verstellung, entlarvung, lügen aller art sind verwendet wie in vielen anderen stücken. So kehrt die vorspiegelung eines todesfalles aus M. b., die doppelgängerschaft aus B. B., der herunterfallende brief aus L. C. wieder, usw. - Der nicht einzuschüchternde schwerenöter erschien schon in L. V., der England verachtende geck in B. D., der heuchelnde fromme erinnert an Mrs. Plotwell's verstellung (B. D.), der hilfreiche freund an Frederick (W.S.). - Aber die anwendung der motive und das gebiet der charakteristik sind neu, die letztere ist vorzüglich und beschäftigt sich mit realistischen spezialitäten. Insbesondere der quäker und seine frau, der kaufmann und der raritätenschwärmer sind sehr gut getroffen. Dals bei der aufführung Fainwell am besten gefallen hat, erklärt sich daraus, dals er alle jene karrikiert und hineinlegt. Eine solche figur hat bei gutem spiel stets die lacher auf ihrer seite! Für uns ist Fainwell durchaus nicht die interessanteste gestalt. - Der epilog beschäftigt sich auch mit ihm und stellt ihm das grö[ste lob aus.

That Man be mine, who like the Col'nel here, Can top his Character in ev'ry Sphere;

Who can a thousand Ways employ his Wit, Out promise Statesmen, and out cheat a Cit: Beyond the Colours of a Trav'ller paint, And cant, and ogle too - beyond a Saint. The last Disguise most pleas'd me, I confess, There's something tempting in the preaching Dress: And pleas'd me more than once a Dame of Note, Who lov'd her Husband in his Footman's Coat.

Die letzte verkleidung (nämlich als quäker) scheint auch sonst die meiste wirkung ausgeübt zu haben; auf sie geht die redensart "the real Simon Pure" zurück.

Zwei besonderheiten des stückes, die der dichterin zum lobe gereichen, sind erstens die straffe einheit, die mit der tradition der doppelten liebeshandlung bricht, zweitens die vorführung von gemäldeartigen ausschnitten aus dem täglichen leben, des weinhauses, des parkes, des kaffeehauses. - Es hat trotz allen spafses einen tiefen sinn: Schmeichle den schwächen der menschen, und sie werden deine freunde! 
Vier jahre vergehen, bis, ein oder zwei jahr vor ihrem tode, der dichterin letztes werk, A., erscheint. Der form nach ist es wieder ein rückschritt. Denn es ist aus drei fabeln zusammengestellt, die im grunde genommen nichts mit einander zu tun haben. Die schwächste stelle dieses stückes ist wohl die überraschungsszene des dritten aktes (s. in der diss. episode 2), die durchaus nichts mit dem gang der handlung zu tun hat.

Die haupthandlung soll gewifs die von den beiden brüdern getragene sein; deren thema ist von den sonst behandelten stoffen weit verschieden. Es handelt sich um die sühne einer schuld. Der jüngere Freeman hat einst ein mädchen verführt, die ihn nun durch eine list dem tod gegenüberstellt. Der bösewicht ist auch feig und wird in seiner todesfurcht windelweich. - Sehr tief ist das problem also nicht gefa[st. Noch ein andres ist damit verbunden, nämlich das der feindlichen brüder. Im ersten akt sieht es aus (s. das gespräch zwischen Sir John und Ned), als sollte es tiefer behandelt werden. Doch hört diese tendenz bald auf.

Im verhältnis $\mathrm{zu}$ früheren stücken mufs man die klare realistik einzelner züge, die scharfe beobachtungsgabe, die gute motivierung anerkennen. - Die psychologische feinheit bei der ehebruchhandlung Watchit-Ned ist bisweilen auffallend. So sagt z. b. Watchit (317): "If she has cuckolded me, tho" but in Thought" usw. Auch das selbstgespräch im fünften akt zeigt solche feinheiten: "Hark! Sure I heard somebody tread, - No, 'twas nothing but the Wind, I believe - 'Tis very cold - I shall catch my Death; but it is better to die once for all, than to live upon the Rack."

Realistisch ist auch, dafs der ehemann nicht etwa (wie z. b. in B. T.) als ein ausbund von dummheit hingestellt wird: die männer brauchen gar nïcht so dumm zu sein, um von ihren frauen betrogen zu werden. - Die verstellungskunst der frau ist feiner dargestellt als in M. L.

Auch die handlung, die die übertölpelung der witwe darstellt, zeigt grofse feinheiten. $\mathrm{Da}$ ist zunächst Tally mit seinem gemisch von feigheit und frechheit. Der typus des hochstaplers hat sich seit Pl. L. entwickelt! - Feinheiten in der beobachtung sozialer verhältnisse zeigen die erörterungen zwischen Fainwell und der witwe (s. Anglia. N. F. XX; s. 472). - Dem fähnrich Fainwell haftet trotz seiner munterkeit etwas Anglis. N, F. XXI. 
auffallend hausbackenes an, das ihn bewegt, durch überlistung der witwe und Tallys sich das warme plätzchen an herde zu sichern. - Die witwe Heedless ist in ihrem gemisch von schwäche und ehrbarkeit eine sehr gelungene figur.

Das endurteil über A. ist, dals die intriguen zugunsten tieferer lebens- und seelenbeobachtung zurücktreten, daIs Mrs. Centlivre auf dem wege zu ruhiger, abgeklärter realistik ist.

Die quellen sind nicht bekannt. Die beziehungen zu früheren stücken aber sind sehr zahlreich. Hohrmann erinnert daran, dafs die einwilligung eines vaters, der zuerst dem wunsche der tochter widerstrebt, aber durch eine erbschaft umgestimmt wird, sich in Molières Le Médecin malgré lui findet; das ist richtig. Sie findet sich aber auch in St. H. (ende). Aus L. C. könnte der umstand stammen, dals der vater anfänglich eben die verbindung der tochter gewünscht hat, der er dann widerstrebt, weil ein reicherer liebhaber auftritt. Die charaktere der väter in beiden stücken ähneln sich fast aufs haar. - Fainwell erinnert an seinen namensbruder in B. Str., mit seiner fertigkeit in der dialektnachahmung an Isabella in Pl. L., Mrs. Heedless an Mrs. Dowdy ebenda, das auftreten des viel bedauerten und beweinten mädchens an die heuchelei Isabellas ebenda, Tally an Sharper; das verhältnis FainwellWidow-Tally ist gegen dasjenige Belvil-Widow-Sharper (Pl.L.) insofern verschoben, als in $\mathrm{A}$. die witwe dem ehrlicheren mann anheimfällt. - Die hausszene bei Mrs. Heedless erinnert an diejenige bei Mrs. Dowdy (Pl.L.). - Die ehebruchszene in A. zeigt enge verwandtschaft mit derjenigen in L. V., wo auch die frau über die dreiste stirn des verführers dem gatten gegenüber entzückt ist. Dals ein mann trotz der fehler seiner frau in diese verliebt ist und diese liebe sich in bewunderung einer ihm besonders niedlich erscheinenden einzelheit ihres äufseren zeigt, erinnert an Sago in B. T.; dort hören wir:

"Ah! that Hand, that Hand it was which first got hold of my Heart" (225); und "my Keecky, shew me thy little Finger agen - 0 dear little Finger, my Keecky!"

In A. aber sagt Matchit (317):

"Odd, I can't put this Foot of hers out of my Head; it looks like an Excuse to conceal some secret Failing"; und (349): "Oh! 'twas that bewitching Leer, that snapt my Heart." 
Die vorgeschützte reise erinnert an die reise Pedros in M. L., an die Gripes in B. B., die verbindungstür zweier häuser kommt schon in P. L. vor. - Dafs ein umworbenes mädchen fast noch im letzten augenblick vor der entscheidung bedenken geltend macht, ist schon in M. b. und B. B. dagewesen. - Die überrumpelung Neds erinnert etwas an diejenige der Lady Reveller (B. T.).

So erklärt sich immerhin ein teil des A. aus den früheren werken. Eine grofse relative selbständigkeit nimmt nach den vorhergehenden untersuchungen bei unsrer dichterin nicht wunder. - Übrigens bestätigt sich gerade bei dem vergleich jener beziehungen zu früheren stücken das oben (s. 114) über A. gefällte urteil.

Uber die selbständige kraft der dichterin ist nach allem gesagten kein wort des beweises mehr zu verlieren. Sie hat hinreichende phantasie, eine gestalt in sich entstehen zu lassen, und hinreichende gestaltungskraft und technik, sie uns lebendig zu machen. Ihre darstellung ist nach allen möglichen richtungen vorzüglich. "Mrs. Centlivre had an obtrusive humour, sayings full of significance rather than wit, wholesome fun in her comic, and earnestness in her serious, characters. Mrs. Centlivre, in her pictures of life, attracts the spectator" (Doran I, 245). Es wird dann die wahrheit, gefälligkeit und innigkeit ihrer dichtung gerühmt; "the grouping perfect, the colour faithful, and enduring too - ". Man kann kaum mehr des lobes über sie sagen, und nichts richtigeres. Doran fügt aber hinzu: "There may be, now and then, something, as in Dutch pictures, which had been as well away." Auf diesen punkt müssen wir des näheren eingehen.

Es gibt nichts uniichtigeres als Mrs. Centlivre mit Aphra Behn zusammenzustellen. Jene ist sowohl bedeutend gröfser als diese, als auch moralischer. ${ }^{1)}$ Unmoral ist es, das schlechte zu vertreten, wenn man das gute kennt. Tut das Mrs. Centlivre auch nur ein einziges mal?! - Sie ist derb; nicht gemein und nicht zimperlich. Was gewöhnlich bei ihr als unmoralisch bezeichnet wird, ist allenfalls geschmacklos. Wenn recht

1) S. auch das Anglia. N.F. XX, s. 447 ff., s. 450 ff. u. s. 458-462 gesagte. 
häufig "cuckoldom" erwähnt wird, so ist das vielleicht unschön. Es wird aber doch nur erwähnt, um der furcht des ehemannes davor ausdruck zu geben, oder um die niedrige gesinnung eines menschen zu kennzeichnen, dem dann immer gegenspieler oder verhältnisse gegenüberstehen, die es nicht zweifelhaft erscheinen lassen, wie die dichterin denkt. Sie erkennt mit klarem blick die lebensverhältnisse, wie sie sind; in ihrem realistischen drang schildert sie sie auch; aber immer führt sie den grund mit an, der zu dem unerfreulichen ergebnis geführt hat, so insbesondre die verbindung von ehegatten, die in alter und gesinnung nicht zu einander passen. Auch kommt in ihren stücken kein ehebruch zustande; gewöhnlich endet die entsprechende handlung mit dem besserungsvorsatz des schuldigen teiles. Dals man dem mann eine abirrung einmal verzeiht, wie Isabinda in M. L. tut, ist ja leider auch zum teil heut noch wahr und nicht nur in einer zeit, von der Brosch (Geschichte Englands, III, 104) sagt: "Von der korrumpierenden herrschaft der zwei letzten Stuartkönige war im lande ein bodensatz von gemeinheit geblieben, der den sinn für niedriges bei vielen und den meisten, den für hohes und erhabenes nur bei den wenigsten aufkommen liefs." In jenem fall verfährt Mrs. Centlivre nur realistisch.

Wie kann jemand, der wiederholt den kampf der frau um ihre ehre (Lady Wealthy in G.; Lady Reveller in B. T.; Widow Heedless in A.) als ausschlaggebend für ihr ganzes leben hinstellt, für unmoralisch gelten! Fast pedantisch ist die dichterin mit bezug auf weibliche wesen. Man denke nur an Lucy in B. T. - Wie engherzig rückt Isabella in Pl. L. von der Dowdy ab (249), als der ruf dieser witwe zweifelhaft wird. Mit zimperlicher gewissenhaftigkeit rechtfertigen Isabella und Lucinda ihre listigen streiche (Pl. L. I, 205, wo Lucinda zu Belvil sagt: "Come, my Maid's with me, I'll go now and drink some Tea with you." Isabella überlegt II, 209: "Do I value Reputation? - Yes, as much as any body does that follows their Inclination - Ay, but whither will that Inclination carry me? Why, not beyond the Rules of Honour.").

Aus mancher stelle hört man deutlich die verachtung, die die anständige frau der mätresse entgegenbringt, und kann daraus erfreuliche schlüsse auf das leben der dichterin ziehen. 
Selbstzweck ist die gemeinheit bei ihr nie. - Die notzucht wird in A. verwendet, aber im verlauf scharf verurteilt. - Den schlechten werden stets vertreter des besseren gegenübergestellt.

Nun soll mit dem vorhergehenden nicht etwa gesagt sein, dals die gedanken unsrer dichterin nur hohen, idealen flug nehmen. Das schlofs sich schon durch den zweck aus, dem ihre dichtung diente. Das publikum hätte sich kaum mit aufgeschwungen. Und Mrs. Centlivres ziel war doch im wesentlichen kassenerfolg! Es kam noch hinzu, dafs ihre versuche in der tragischen dichtung gar keinen erfolg hatten. - So hielt manches sie in der sphäre des täglichen lebens, aus dem auch abstolsende züge in ihre werke übergegangen sind.

Es betrifft das insbesondere das verhältnis der kinder zu den eltern. Da lachen zwei väter (in L. C. und in A.) höhnisch über das moralische empfinden ihrer töchter! Mütter spielen gar keine rolle. Nur einmal erwähnt ein kind die mutter: Olivia (A. II, 305) sagt $\mathrm{zu}$ ihrem vater: "Oh do not name my Mother! Were she alive, you would not treat me thus." - Vielleicht ist dieses eindringliche wort der dichterin aus dem innersten herzen gekommen, die ja nach dem tode ihrer mutter wegen schlechter behandlung geflohen sein soll. Ist diese einzelheit reine vermutung, so hat die allgemeine annahme, dals sie elternliebe wenig kannte, durchaus wahrscheinlichkeit. Irgend ein abglanz solchen gefühls mülste sich spüren lassen. - Aber nur kalt, nicht unmoralisch denkt sie selbst in diesem punkte; denn die pflicht des gehorsams der kinder ist oft betont.

Das leben der Mrs. Centlivre ist bisher nur in wenigen zügen bekannt. Allzu bitter können ihre erfahrungen nicht gewesen sein. Sie sieht die menschen mit freundlichem auge an. Sie malt sie, wie sie über kleine milshelligkeiten dem glück entgegengehen. Ihre werke stellen ihre lieblinge in den heiteren sprïngen bis an die schwelle vermögenden philistertums dar.

Die besten stücke der jugend unsrer dichterin, vor allem The Gamester, zeigen sie als idealistin. Sie ist etwa 25 jahre alt. In dieser zeit glaubt man noch an die besserungsfähigkeit der menschen. Der gute wunsch der dichterin ist malsgebend für die charakterwandlung ihrer helden. - Später wird man 
skeptischer. Aber die beobachtung vertieft sich. Sie malt nun die menschen nicht mehr, wie sie sein sollen, sondern wie sie sind. Das komische reizt zunächst zur darstellung. Marplot ist das beste ergebnis dieser wandlung. - Dann wendet sie sich dem geheimnisvollen, problematischen des charakters zu. W. S. und B. Str. sind die ergebnisse: jenes ist der triumph ihrer charakterdarstellung, dieses hat einen starken einschlag des realistischen. Sie ist etwa 35 jahre alt. - Ihr letztes werk ist A., sie falst es mit reichlich 40 jahren ab. Die realistik der charaktere, die ruhe der beobachtung dringen hier am meisten durch. - Sie starb bald nachher.

Enttäuschungen und anfeindungen sind ihr bei ihrem streben natürlich nicht erspart geblieben, wie aus dem Schicksal von L. V. und aus den vorworten von M. b. und P. L. erhellt.

Die denkweise der Mrs. Centlivre ist gesund. Sie kann mülsiggänger und heuchler nicht leiden. Sie tadelt scharf den hochmut der oberen gegen die niederen. Aber sie erkennt die schwächen, die die engen verhältnisse der niederen und erwerbenden stände mit sich bringen. - Ihre soziale kritik ${ }^{1}$ ) hat etwas ungemein redliches. Sie schaut mit offenen munteren augen um sich, das ziel ihres strebens und denkens liegt gerade aus.

Ihre kenntnisse werden wohl oft überschätzt; insbesondre im vorwort zu der hier benutzten ausgabe (s. Anglia. N.F. XX, s. 436). Belegt ist bisher nur ihre gute kenntnis des Französischen. Aber grofse belesenheit steht aufser frage.

Das politische element spielt in die hier behandelten komödien wenig hinein; zum glück, kann man sagen. Dieser tendenz huldigt nur der einakter Gotham Election. - Aber die dichterin war eine gute patriotin, und ihre politische farbe bekennt sie mit klugheit und schwung im vorwort zu P. L.: "I know not what they call Whigs, or how they distinguish between them and Tories: But if the Desire to see my Country secur'd from the Romish Yoke, and flourish by a firm, lasting, Honourable Peace, to the Glory of the best of Queens, who deservedly holds the Balance of all Europe, be a Whig, then

1) S. Anglia. N.F. XX, s. $471 \mathrm{ff}$. 
I am one, else not." - Und sie ist nicht fanatisch; beweis ist folgendes gespräch in M. b. (I, 149):

"Sir Jeffrey: Why, what Objections can he (ein vater) make against Mr. Lovely?

Trusty: Only Principles: Her Father's a violent Tory, and this honest Gentleman's a Whig, that's all.

Sir Jeffrey: Ha, ha, a strong Reason, Faith."

Auch hier gesunder menschenverstand!

So steht ein sympathischer geist in dieser frau vor uns, die mit hellen augen in die welt schaut und das gesehene mit natürlichkeit und heiterkeit darbietet, wobei sie unbefangen der formen sich bediente, die sie vorfand.

Ihr äufseres möge unsre eindrücke vervollständigen. Herr Centlivre, der königliche koch, hat sich in sie verliebt, als er sie in einer mänuerrolle sah; ein günstiges zeichen für ihre gestalt und ihr wesen. Ihr gesicht zeigt uns ein holzschnitt, den Doran (I, 237) überliefert: ein regelmälsiges, fast liebliches antlitz mit kräftigen zügen, aus denen wohl eine gesunde sinnlichkeit spricht, und grolsen, milden, klugen augen.

BerLin.

ROBert SEIBT. 